$12-3-2019$

\title{
Visual Storytelling and Vulnerable Healthcare Consumers: Normalising Practices and Social Support Through Instagram
}

\author{
Lauren Gurrieri \\ RMIT University \\ Jenna M. Drenten \\ Loyola University Chicago, jdrenten@luc.edu
}

Follow this and additional works at: https://ecommons.luc.edu/business_facpubs

Part of the Business Commons

\section{Author Manuscript}

This is a pre-publication author manuscript of the final, published article.

\section{Recommended Citation}

Gurrieri, Lauren and Drenten, Jenna M.. Visual Storytelling and Vulnerable Healthcare Consumers: Normalising Practices and Social Support Through Instagram. Journal of Services Marketing, 33, 6: 702-720, 2019. Retrieved from Loyola eCommons, School of Business: Faculty Publications and Other Works, http://dx.doi.org/10.1108/JSM-09-2018-0262

This Article is brought to you for free and open access by the Faculty Publications and Other Works by Department at Loyola eCommons. It has been accepted for inclusion in School of Business: Faculty Publications and Other Works by an authorized administrator of Loyola eCommons. For more information, please contact ecommons@luc.edu.

\section{c) (†) $\ominus$}

This work is licensed under a Creative Commons Attribution-Noncommercial-No Derivative Works 3.0 License. (c) Emerald Insight, 2019. 
Gurrieri, Lauren and Jenna Drenten (2019), "Visual Storytelling and Vulnerable Healthcare Consumers: Normalising Practices and Social Support through Instagram," Journal of Services Marketing, 33(6), 702720.

Note: This is a preprint version. The final published version of the paper may reflect notable format and content changes.

\title{
VISUAL STORYTELLING AND VULNERABLE HEALTHCARE CONSUMERS: NORMALISING PRACTICES AND SOCIAL SUPPORT THROUGH INSTAGRAM
}

\begin{abstract}
Purpose: The purpose of this study is to explore how vulnerable healthcare consumers foster social support through visual storytelling in social media in navigating healthcare consumption experiences.
\end{abstract}

Design/methodology/approach: This study employs a dual qualitative approach of visual and textual analysis of 180 Instagram posts from female breast cancer patients and survivors who use the platform to narrate their healthcare consumption experiences.

Findings: Our research demonstrates how visual storytelling on social media normalises hidden aspects of healthcare consumption experiences through healthcare disclosures (procedural, corporeal, recovery), normalising practices (providing learning resources, cohering the illness experience, problematising mainstream recovery narratives) and enabling digital affordances, which in turn facilitates social support among vulnerable healthcare consumers.

Practical implications: Our research highlights the potential for visual storytelling on social media to address shortcomings in the healthcare service system and contribute to societal wellbeing through co-creative efforts that offer real-time and customised support for vulnerable healthcare consumers. 
Social implications: This research highlights that visual storytelling on image-based social media offers transformative possibilities for vulnerable healthcare consumers seeking social support in negotiating the challenges of their healthcare consumption experiences.

Originality/value: Our research presents a framework of visual storytelling for vulnerable healthcare consumers on image-based social media. Our paper offers three key contributions: that visual storytelling fosters informational and companionship social support for vulnerable healthcare consumers; recognising this occurs through normalising hidden healthcare consumption experiences; and identifying healthcare disclosures, normalising practices and enabling digital affordances as fundamental to this process.

Classification: Research Paper

Keywords: visual storytelling; vulnerable consumers; health services; breast cancer; social media; social support; selfies 


\section{VISUAL STORYTELLING AND VULNERABLE HEALTHCARE CONSUMERS: NORMALISING PRACTICES AND SOCIAL SUPPORT THROUGH INSTAGRAM}

Both transformative services and social marketing aim to improve people's lives through better services and reduced social inequalities (Russell-Bennett et al., 2013). However, a challenge in the delivery of service systems that distribute well-being benefits to consumers lies in the range of vulnerabilities such consumers may experience. Consumer vulnerability arises "when a person is powerless, out of control, and dependent in a consumption situation that has negative ramifications on one's identity" (Baker et al., 2005). In response to experiencing vulnerability, consumers engage in a variety of behavioural coping strategies, including seeking out social support from community and family networks (Wang and Tian, 2014, Broderick et al., 2011, Hamilton, 2009). Yet, the availability of social support in contemporary societies has lessened and traditional support systems may break down for some consumers (McKeage et al., 2018). Consequently, individuals increasingly seek out social support from commercial service providers (Gentry and Goodwin, 1995). Whilst such "commercial friendships" (Price and Arnould, 1999) can be helpful for consumers in terms of their well-being (Rosenbaum, 2009), they may also affect behaviour in ways that may be harmful (Zhu et al., 2012). This speaks to the inequalities that can arise in service encounters between consumers and service providers (Lee et al., 1999). Moreover, incentives do not always exist for organisations to (re)address the wellbeing of consumers who are subject to various vulnerabilities (Shultz and Holbrook, 2009). This is compounded by the fluidity of vulnerability and the ability to address the needs of the newlyvulnerable as conditions evolve (Canhoto and Dibb, 2016).

One way in which consumers negotiate these tensions is through the use of technologybased service solutions that connect consumers and in turn enhance well-being, such as socially supportive resources offered via internet-mediated support groups (Parkinson et al., 2017) or mobile device applications (Schuster et al., 2013). Online communication tools offer consumers the ability to seek and share a range of market-orientated information (Cova and Pace, 2006, Mathwick et al., 2008). This is critical given the potential for information voids in the marketplace to contribute to consumer vulnerability (Baker et al., 2005, Baker et al., 2007, Price et al., 1995). Such consumer-to-consumer interactions have given rise to a range of online 
consumption communities that offer consumers social support (Kozinets et al., 2008). In turn, this helps to reduce consumption-orientated risks and enhance consumption context control (Belk and Tumbat, 2005, Mathwick et al., 2008, O'Sullivan, 2015) and offers needed social support for consumers with limited access to other forms of support (McKeage et al., 2018). The provision of social support through virtual communities may furthermore promote health outcomes (McCormack, 2010) and enhance quality of life (Tang et al., 2015). Yet, underexplored is how vulnerable consumers foster social support in the interactive and networked Internet-based applications of social media (Parkinson et al., 2017).

An emerging stream of research highlights the role of storytelling in improving the wellbeing of vulnerable consumers (Visconti, 2016). Social media, in particular, is increasingly a space for sharing stories, offering identity-oriented narratives and interpersonal connections for both tellers and audiences (Page, 2012). Society is increasingly preferential toward online conversations that include images and photos, which increase feelings of connectedness (Wortham, 2013). Thus, we specifically consider a form of storytelling that increasingly takes place on social media, namely visual storytelling. The aim of this research is to examine the intersection of social media, visual storytelling and social support in the context of how vulnerable consumers navigate healthcare consumption experiences. That is, we explore visually-based stories told by vulnerable consumers in healthcare services, including those which take place outside of the healthcare setting. This comprehensive view is important as the care process does not cease when a customer leaves a healthcare setting (McColl-Kennedy et al., 2012). Our research demonstrates how vulnerable healthcare consumers engage in visual storytelling on Instagram through healthcare disclosures: procedural disclosures, corporeal disclosures and recovery disclosures. These disclosures work to normalise hidden healthcare consumption experiences through three normalising practices: providing learning resources, cohering the illness experience and problematising mainstream recovery narratives. In turn, this fosters both informational and companionship support for vulnerable healthcare consumers. The digital affordances of image-based social media (e.g., Instagram), such as tagging, hashtagging and commenting, are fundamental in facilitating this process. We contend that normalising hidden healthcare consumption experiences through visual storytelling on social media is an important means of fostering the social support needed to address the vulnerabilities of healthcare consumers. Moreover, this attends to shortcomings in the healthcare service system 
and speaks to the important role and co-creative influence of the healthcare consumer, which to date in social marketing research examining illness, recovery and health has been curiously absent.

In attending to this aim, our paper is structured as follows. First, we review literature on storytelling as a means of providing social support for healthcare consumers throughout their illness experiences. We highlight that visual storytelling remains under-explored to date in this domain. Second, we present our qualitative research study of Instagram posts from female breast cancer patients and survivors who use the image-based social media application to visually and textually narrate their healthcare experiences. Third, our research findings highlight how visual storytelling on social media normalises hidden aspects of healthcare consumption experiences through healthcare disclosures, normalising practices and enabling digital affordances, in turn fostering both informational and companionship support among vulnerable healthcare consumers. Finally, we conclude that visual storytelling on image-based social media offers transformative possibilities for vulnerable healthcare consumers seeking social support in negotiating the challenges of their healthcare consumption experiences. Our research presents a framework of visual storytelling for vulnerable healthcare consumers on image-based social media, that offers three key contributions: (1) that visual storytelling fosters social support for vulnerable healthcare consumers; (2) recognising this occurs through normalising hidden healthcare consumption experiences; and (3) identifying healthcare disclosures, normalising practices and enabling digital affordances as fundamental to this process. This research highlights the agency of vulnerable healthcare consumers in managing their illness experiences, the transformative role of technology for those experiencing such vulnerability and the potential for visual storytelling on social media to address shortcomings in the healthcare service system and contribute to societal well-being through co-creative efforts. To explicate our approach, the paper now turns to literature on storytelling and social support in digital media for those experiencing vulnerability in relation to their health.

\section{Storytelling, Social Support and The Illness Experience}

Telling stories is a universal form of communication through which people are able to represent their self-reflected experiences and understanding of the world (Frank, 2000). 
Storytelling furthermore houses the potential to subvert the structures that reinforce consumer vulnerability (Visconti, 2016). Expressing oneself through storytelling and the exchange of experiences is an important coping strategy for healthcare consumers, making their world more comprehensible, manageable and meaningful by providing a 'sense of coherence' (Varre and Slettebø, 2011). Central to this, is the ability of individuals to have more meaningful control over how their experiences of illness are represented (Orgad, 2005). Storytelling also enhances disease self-management and enables individuals to take a more active role in their healthcare by identifying specific needs, highlighting gaps in knowledge and skills and allowing strong bonds to be formed with others who share similar disease-related experiences (Gucciardi et al., 2016). Storytelling that takes place online, such as in internet-based groups, increases social support by reducing social isolation and increasing patients' personal empowerment and self-esteem (Høybye et al., 2005, Keim-Malpass and Steeves, 2012).

Social support is the functional content of relationships and can be categorised into four broad forms (Berkman et al., 2000, Cohen and Syme, 1985, Tang et al., 2015): (1) emotional support involves the provision of empathy, love, trust, and concern that signals a person is valued and cared for; (2) instrumental support involves the provision of life-related resources that practically assist a person in need; (3) informational support is the provision of advice, guidance, suggestions, and information that a person can use to address problems and form possible solutions; and (4) companionship refers to groups, discussions and other social activities that help people recognise they are part of something larger and affirmative. Previous research suggests social support needs met through the internet are unlikely to be met through conventional healthcare, such as addressing social isolation and forming social connections with likeminded others (Ziebland et al., 2004). This speaks to the identity negotiations one experiences when becoming ill and the often limited value of medical conceptualisations of health and illness in helping people 'make sense' of their illness (Frank, 2013, Frank, 1997). By 'telling their story', healthcare consumers are able to share personal experiences related to their diagnosis, treatment and consumption of health services (Eysenbach et al., 2014). In turn, storytelling can enable healthcare professionals to gain greater insight into the needs of healthcare consumers and how they navigate, manage and cope with their illness (Gucciardi et al., 2016, Egan et al., 2016). Well-produced stories that express the personal and social impacts of illness on everyday life can also provide useful learning for others (Yu et al., 2011). For this 
reason, patients' stories tend to be widely collected and used to support a range of functions for self-help and voluntary groups, including creating databases of patient experiences, training staff and volunteers and to inform treatment (Yaphe et al., 2000).

Visual storytelling offers a particularly impactful means for coping and personal transformation at different stages of an illness (Gonzalez-Dolginko, 2016). Illness-related images narrate healthcare consumers' lived experiences, in turn facilitating self-expression, fostering self-reflection and heightening self-management of the illness (Drew et al., 2010). Research has demonstrated that visual storytelling formats (e.g., personal stories via video) are preferred for collecting healthcare related information and fostering support (Angell et al., 2015). Visual storytelling can also help meet the needs of healthcare service providers, such as efficiently communicating patient histories or ailments (McCurdy, 2016). This is reflected in the history of photovoice methodology in health studies, where patients are encouraged to collectively take part in a photographic project that focuses on issues of concern to them by photographing the 'reality' of their everyday experiences (Carlson et al., 2006, Wang et al., 1998).

Yet, to date visual storytelling in health domains tends to focus on patient generated images that are employed for collective exhibiting purposes or as elicitation devices in interviews with researchers (Drew et al., 2010). Missing from the picture is the new wave of visual storytelling that is captured through image-based social media applications, such as Instagram. The use of such applications enables medical issues to be broken down into more manageable and consumable components, with individuals able to share their illness stories with ease (Lau, 2017). Moreover, direct and explicit expressions of one's experience throughout an illness can be communicated readily via social media (McCosker and Darcy, 2013). Hence, this study investigates: (1) how vulnerable healthcare consumers engage in visual storytelling on social media; (2) how this process fosters social support between vulnerable healthcare; and (3) the implications of this for the healthcare service system.

\section{Context and Methodology}

To examine these research questions, we turn to Instagram, an image-driven social media site with over 800 million active users each month (Statista 2017). Relative to other social media sites (e.g., Facebook, Twitter, blogs), Instagram is unique because it is fundamentally rooted in visual media. That is, all posts must contain a picture or video. Additional text (e.g., captions, 
hashtags, emojis) is optional but frequently used. Instagram allows users to interact by commenting on and liking one another's posts. This study employs a dual qualitative approach of visual and textual analysis of Instagram posts from female breast cancer patients and survivors who use the platform to narrate their healthcare consumption experiences.

Being diagnosed with cancer accentuates human vulnerabilities (Timko and JanoffBulman, 1985). Indeed, breast cancer patients experience increased feelings of vulnerability, loss of control, and uncertainty about their future (Arora et al., 2007). Breast cancer carries with it physical risks (e.g., fatality), social stigma (e.g., perceived loss of femininity), and long-term healthcare concerns (e.g., chance of recurrence). In line with previous research, breast cancer patients and survivors can be considered vulnerable healthcare consumers given their powerlessness in the healthcare service setting and circumstances which may negatively affect their sense of self (Baker et al., 2005, Parkinson et al., 2017). Moreover, breast cancer is a compelling context to explore the transformative potential of storytelling, given the pervasiveness of dominant breast cancer narratives (Wong and King, 2008). Our study seeks to understand vulnerable healthcare consumers' healthcare consumption experiences related to breast cancer as they engage in visual storytelling on Instagram.

Instagram profiles in our study were initially identified by searching for common hashtags related to breast cancer, including \#breastcancersurvivor, \#mastectomy, and \#triplenegativebreastcancer. Snowball sampling was employed by clicking on related hashtags and suggested profile pages. This process resulted in a sample of 18 women who self-identify as breast cancer patients and survivors on their Instagram profiles. Table 1 provides the profile bio from each woman's Instagram page, in addition to her country, cancer status, and online follower information at the time of data collection. Each woman's Instagram page functions as a narrative of her life, in real-time, as she progresses through her experience of coping with breast cancer. In line with previous online research exploring vulnerable healthcare consumers' narratives, our study takes a naturalistic qualitative research approach to analysing Instagram pages already in existence and made public (Keim-Malpass and Steeves, 2012, Keim-Malpass et al., 2014). Naturalistic inquiry is a qualitative research method used to examine people's life experiences in context-bound settings (Lincoln \& Guba, 1985) — in this case, breast cancer patients' and survivors' healthcare consumption experiences as narrated through Instagram. Naturalistic qualitative research is appropriate for describing, analysing, and interpreting people's lived 
experiences, interactions, and language (Armstrong, 2010). Researchers begin by immersing themselves in the natural setting to become familiar with the context, in order to "question their own assumptions and act like strangers to the setting as 'naïve' observers" (Flick, 2009, p. 12). Immersion can begin before formal data collection, for example, through active observation of Instagram posts or exploring interactions between users.

Table 1. Sample of Instagram Profiles

\begin{tabular}{|c|c|c|c|c|c|}
\hline Pseudonym & Profile Caption & Country & $\begin{array}{l}\text { Cancer } \\
\text { Status }\end{array}$ & Followers & Following \\
\hline Izzy & 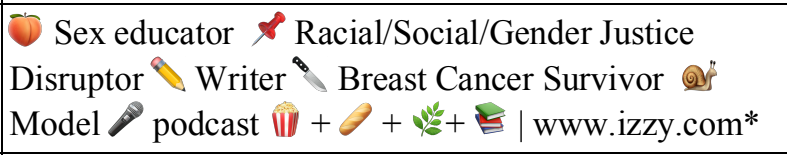 & USA & Survivor & 98,900 & 3,529 \\
\hline Sara & $\begin{array}{l}\text { Self taught MUA [makeup artist]. BBW [big beautiful } \\
\text { woman]. Tall drink of water. Unicorn Mermaid } \\
\text { Seductress. Body \& Sex positive. Human Lover. } \\
\mathbb{E}: \text { sara@gmail.com | www.patreon.com/sara* }\end{array}$ & UK & Survivor & 26,900 & 1,219 \\
\hline Poppy & $\begin{array}{l}\text { I beat cancer before it got the chance to beat me } \\
\text { Scars are sexy Self love \& bopo Your new breast } \\
\text { friend } \\
\text { www.poppycancer.com/mailinglist* }\end{array}$ & USA & Survivor & 20,000 & 1,223 \\
\hline Molly & $\begin{array}{l}\text { Pocono to Pittsburgher } V \text { occupational therapist by } \\
\text { day } 8 \text { 2B breast cancer superhero by night } \$ \text { shop: } \\
\text { http://mollyboutique.com | mollyboutique.com* }\end{array}$ & USA & Survivor & 11,800 & 1810 \\
\hline Brenda & $\begin{array}{l}\text { Fighting Breast Cancer With Style in Mind - Triple } \\
\text { Negative Metastatic | www.brenda.com* }\end{array}$ & USA & \begin{tabular}{c|} 
In \\
Treatment
\end{tabular} & 10,000 & 821 \\
\hline Gigi & 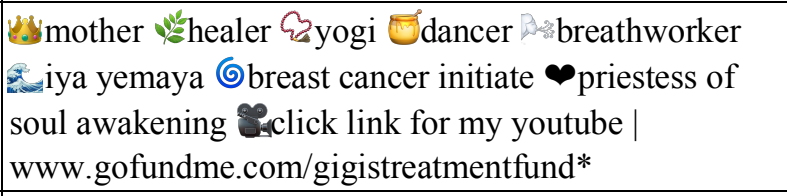 & USA & $\begin{array}{c}\text { In } \\
\text { Treatment }\end{array}$ & 4,078 & 363 \\
\hline Maura & My breast cancer journey, survival and beyond. & USA & Survivor & 3,519 & 1,614 \\
\hline Kristal & $\begin{array}{l}\text { \#MYCUREISONTHEWAY \#IFIGHTEVERYDAY } \\
\text { \#METAVIVOR 3X \#BREASTCANCER } \\
\text { \#BEATINGSTAGE4CANCER \#HEALTHYFAITH } \\
\text { \#BREASTLESS \#BALD | Facebook: Kristal Jones* }\end{array}$ & USA & $\begin{array}{c}\text { In } \\
\text { Treatment }\end{array}$ & 2,854 & 2,456 \\
\hline Julia & $\begin{array}{l}\text { Happy, Alive } \& \text { built to Survive } \odot \mathscr{b} \text { Hubby } \\
@ \text { juliashusband* } 8 \text { Dodgers are life } \bigcirc \text { Breast } \\
\text { Cancer Thriver } b \text { Believer in Jesus } d\end{array}$ & USA & Survivor & 2,853 & 943 \\
\hline Karen & $\begin{array}{l}\text { Breast cancer badass, blogger } \& \text { advocate } \$ \text { And } \\
\text { wearing my scars proudly } b \text { My uncensored life } \\
\text { through cancer below } \& \mid \text { karen.blogspot.ca* }\end{array}$ & Canada & $\begin{array}{c}\text { In } \\
\text { Treatment }\end{array}$ & 2,118 & 1,571 \\
\hline Carolyn & $\begin{array}{l}\text { Breast Cancer at } 30 \text {. DX } 1 / 11 / 17 \text {. Triple Negative. } \\
\text { Dignicap. Sharing my story to help other women in }\end{array}$ & USA & \begin{tabular}{c|} 
In \\
Treatment
\end{tabular} & 1,726 & 793 \\
\hline
\end{tabular}




\begin{tabular}{|c|c|c|c|c|c|}
\hline & \begin{tabular}{|l|} 
their fight against breast cancer. \\
www.localnews.com/lifestyle/health/breastcancer.html*
\end{tabular} & & & & \\
\hline Lana & $\begin{array}{l}\mid \square \text { 23. triple negative breast cancer survivor } \\
1 \text { peter 5:10| www.cancergrad.org/lana* }\end{array}$ & USA & Survivor & 1,702 & 815 \\
\hline Macy & $\begin{array}{l}\text { En descuidos crearemos universos } \mathrm{C} \bullet 8 \mathrm{Mi} \\
\text { blog } \& \mid \text { macy.blogspot.com.es* }\end{array}$ & Spain & \begin{tabular}{|c|} 
In \\
Treatment
\end{tabular} & 1,549 & 1,058 \\
\hline Alyson & 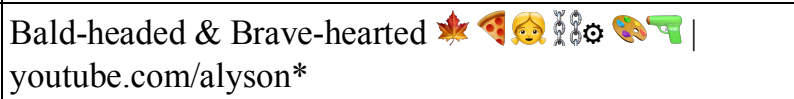 & USA & \begin{tabular}{c|} 
In \\
Treatment
\end{tabular} & 1,216 & 1,085 \\
\hline Amy & $\begin{array}{l}\text { Positive girl fighting triple negative breast cancer 2B } \\
\text { G3 } Q \text { awareness \& motivation like others have for me } \\
\text { | www.caringbridge.org/amy* }\end{array}$ & USA & Survivor & 1,013 & 800 \\
\hline Jennifer & $\begin{array}{l}\text { This is my happy place } 1900 \text { With all due respect for } \\
\text { diseases, even though it's unfair - Life is now } \\
\text { \#fuckcancer | www.jennifer.com* }\end{array}$ & Norway & Survivor & 740 & 235 \\
\hline Theresa & $\begin{array}{l}\text { Gym owner. Cancer warrior. All round } \\
\text { WonderWoman. Running a marathon a month in } 2018 \\
\text { for Cancer Trust. Please donate | www.donate.org* }\end{array}$ & UK & Survivor & 632 & 664 \\
\hline Melanie & $\begin{array}{l}\text { Triple Negative Cancer Stg3+++self discovered Nov } \\
\text { 2016: } 5 \text { months Chemo( } 4 \text { xण); } 12 x \text { Taxol); single } \\
\text { Mstcy +implant May; 5months Ochemo } \\
\text { Capcetibine/Xeloda; then Rads till }\end{array}$ & UK & $\begin{array}{c}\text { In } \\
\text { Treatment }\end{array}$ & 589 & 198 \\
\hline
\end{tabular}

Single asterisk $(*)$ indicates content in the profile bio has been adjusted for anonymity.

Table is sorted by number of followers.

Our study commenced through immersion in the profiles across a period of four months and the development of characteristic vignettes for each woman. Each woman's profile was checked weekly, noting new posts and returning to previous posts to explore comments and discussions taking place. This immersion period was critical to understanding the real-time sharing of experiences with breast cancer (e.g., diagnosis, recurrence, remission) and how Instagram users communicate with one another. Given the everyday appeal of Instagram and its archival nature, it was possible to investigate women's breast cancer experiences longitudinally as many of the women's Instagram pages pre-dated diagnosis. For instance, Theresa's first Instagram post was on July 3, 2012. She was diagnosed with breast cancer in October 2015 and posted her first cancer-related image on December 18, 2015. After one year of treatment, she entered remission in 2016 and continued to narrate her post-cancer journey via Instagram. This form of naturalistic inquiry allowed a better understanding of the evolution of women's stories and provided evidence of their liminal healthcare consumption experiences - before, during, and after cancer. 
Following the immersion period, a more systematic analysis progressed by manually downloading 10 posts from each of the 18 women's pages, including the image/video, caption, hashtag(s), date posted, and permanent hyperlink. Instagram profiles and posts examined in the study followed specific inclusion criteria. First, profiles were only included if they self-identified as breast cancer patients or survivors - thus could be viewed as central to the individual's identity. Second, posts included in the data directly addressed experiences related to the individual's cancer journey (e.g., surgery, chemotherapy, recovery, hair growth) — either through the image, caption, or both. Generalized posts, such a photograph of a landscape with no caption, were excluded from the data. In establishing guidelines for Instagram research methods, Laestadius (2017) suggests smaller sample sizes "offer the best opportunity to make sense of Instagram post components as a unit, rather than considering images/videos, hashtags, captions, comments, and likes independently (p. 581). The analysis of small samples of social media-based data allow for deep insights to understand a specific phenomenon among a subset of the online population - such as women's experiences with breast cancer on Instagram (boyd and Crawford, 2012, Kitchin and Lauriault, 2015). In line with previous studies examining user-generated Instagram content and public health issues, the sample size in our study was determined to be "an appropriate volume of data for analysis while still being small enough to engage in the critical but labour intensive qualitative approach that considers each Instagram post as a holistic unit of captions, hashtags, emojis, and image/video" (Laestadius and Wahl, 2017). Based on insights gathered during our initial immersion period, the 10 posts selected from each profile were deemed to be the most representative of and directly related to each woman's breast cancer experience, beginning with diagnosis and moving forward through treatment, remission, and in some cases, relapse. Instagram allows users to post up to 10 images and/or videos as one swipeable post (i.e., swipe left to see more images in the same post). Thus, our downloaded data comprised 265 images and 10 videos across the 180 posts. All data were anonymized and entered into a spreadsheet. Each woman was assigned a pseudonym for anonymity. Other identifying information, such as personalised hashtags and specific names of hospitals, was also removed. Illustrative examples of images used in the findings section of this article were edited using photo-editing and sketching software (e.g., Adobe Photoshop, BeFunky.com) to further protect each woman's anonymity. 
Data were analysed using an iterative, interpretive approach appropriate for naturalistic inquiry (Thompson, 1997). Interpretation involves continuously identifying patterns and themes across the data, while making sense of what these patterns and themes may mean as related to theory. In this study, each Instagram post was analysed independently. Then, the posts were analysed across Instagram profiles to identify patterns and related back to existing literature to develop theoretical insights. Initial active reading of each post involved searching for meanings and patterns, rather than just casually reading the data (Braun and Clarke, 2006). This approach allowed interpretations to emerge from the data alongside the theoretical underpinnings of visual storytelling and social support. In the initial round of analysis, data were sorted into inductively derived categories of visual stories, conceptualised as disclosures (namely; procedural disclosures, corporeal disclosures, recovery disclosures). Previous research identifies disclosures as a critical component in illness narratives (Mishler, 1984) and suggests "studying these stories and silences opens a window on view that are frequently suppressed" (Charmaz, 2002). Moreover, disclosures are an important source of social support (Lomanowska and Guitton, 2016), which is further enabled by the social connectivity of online social networking applications to foster interactions that facilitate interpersonal disinhibition and intimate selfdisclosure (Jiang et al., 2011, Ledbetter et al., 2011). As our analysis developed, subcategories emerged offering insight into how vulnerable healthcare consumers engage in visual storytelling on social media.

In addition to analysing the visual content (e.g., photograph/video) in each post, the text was also analysed (e.g. captions and hashtags) alongside digital affordances (e.g. likes and comments). Previous research suggests text and images are interdependent in storytelling and the combination is worth more than a single format on its own (Bateman, 2014). This concept, sometimes considered 'meaning multiplication' (Lemke, 1998) influenced our decision to seek meaning from both visual content and text in our data. Analysing captions and hashtags was critical to understanding visual storytelling in the online context, given their ability to contextualise the images and videos in each post. For example, common hashtags like \#lifeaftercancer, \#ifighteveryday, and \#thisisbreastcancer offer additional metacommunicative context for the audience. Specific to our study, we were interested in understanding how these online conversations unfold as prompted by visual storytelling on Instagram and their role in 
social support, as related to our theoretical foundation. Comments on each post were analysed to better understand the interactions between Instagram users.

\section{Findings}

Our research findings highlight how visual storytelling on social media normalises hidden aspects of healthcare consumption experiences through healthcare disclosures, normalising practices and enabling digital affordances, which in turn facilitates social support among vulnerable healthcare consumers. We define disclosures as how individuals make known or reveal new or hidden aspects of a particular phenomenon, in this case healthcare consumption experiences, to others. Specifically, in the context of breast cancer, we identify three healthcare disclosures: procedural disclosures, corporeal disclosures, and recovery disclosures. Previous healthcare research suggests consumers hide the more unpleasant or frightening aspects of healthcare consumption (Chuang and Yang, 2010). In contrast, healthcare disclosures reflect healthcare consumers' authentic lived experiences, thereby offering visual stories that normalise various aspects of healthcare consumption experiences. Enabling digital affordances (e.g., geotags, image tags, hashtagging) play a central role in this process, as vulnerable healthcare consumers utilize social media features (e.g., liking, commenting) to facilitate relational interaction and meaning (Bucher \& Helmond, 2016). As hidden aspects of the healthcare consumption experience are normalised through visual storytelling, patients, survivors, and other social media users interact to engage in social support - specifically, informational support and companionship support. Digital affordances such as commenting, liking, and hashtagging enable this support. All of these activities are performed through image-based social media (e.g., Instagram). In Figure 1, we offer a framework for understanding visual storytelling for vulnerable healthcare consumers, specifically highlighting how healthcare disclosures, normalising practices, social support and digital affordances function collectively on imagebased social media. Using evidence derived from the data, we demonstrate how visual storytelling through healthcare disclosures on Instagram allows breast cancer patients and survivors to normalise hidden healthcare consumption experiences, in turn facilitating socially supportive relationships with vulnerable healthcare consumers and others online. 
Figure 1. Framework of Visual Storytelling and Vulnerable Healthcare Consumers






\section{Normalising Hidden Aspects of Healthcare Consumption Experiences through Visual Storytelling on Social Media}

Certain healthcare consumption experiences are often hidden from view or minimised given their sensitive nature, or at times, uncomfortable contexts. Our data show image-based social media provides a platform for visual storytelling, by which vulnerable healthcare consumers engage in normalising hidden aspects of healthcare consumption experiences through three healthcare disclosures - procedural, corporeal and recovery. As vulnerable healthcare consumers share their visual stories on social media, each healthcare disclosure drives three related normalising practices: providing learning resources, cohering the illness experience and problematising mainstream recovery narratives. Breast cancer patients and survivors' healthcare disclosures and normalising practices highlight related implications for the healthcare service system, both inside and outside of the traditional healthcare setting. Table 2 summarises each healthcare disclosure, its normalising practice relative to hidden aspects of the healthcare consumption experience, and implications for the healthcare service system. 
Table 2. Normalising Hidden Aspects of Healthcare Consumption Experiences

\begin{tabular}{|l|l|l|l|}
\hline \multicolumn{1}{|c|}{$\begin{array}{c}\text { Healthcare } \\
\text { Disclosures }\end{array}$} & \multicolumn{1}{c|}{ Definition } & Normalising Practices & $\begin{array}{c}\text { Implications for } \\
\text { Healthcare Service System }\end{array}$ \\
\hline Procedural Disclosures & $\begin{array}{l}\text { The ways in which the } \\
\text { healthcare system is } \\
\text { conducted and experienced, } \\
\text { offering more information } \\
\text { about the hidden technical } \\
\text { aspects involved in healthcare } \\
\text { consumption for vulnerable } \\
\text { healthcare consumers }\end{array}$ & $\begin{array}{l}\text { Providing a learning } \\
\text { resource }\end{array}$ & $\begin{array}{l}\text { Highlights possibilities for } \\
\text { information sharing and co- } \\
\text { creating healthcare services }\end{array}$ \\
\hline Corporeal Disclosures & $\begin{array}{l}\text { The ways in which vulnerable } \\
\text { healthcare consumers } \\
\text { experience and navigate } \\
\text { hidden physical } \\
\text { transformations that result } \\
\text { from the consumption of } \\
\text { healthcare services }\end{array}$ & $\begin{array}{l}\text { Cohering the illness } \\
\text { experience }\end{array}$ & $\begin{array}{l}\text { Helps to better understand } \\
\text { the physical, bodily needs of } \\
\text { or challenges faced by } \\
\text { healthcare consumers }\end{array}$ \\
\hline Recovery Disclosures \\
$\begin{array}{l}\text { The ways in which vulnerable } \\
\text { healthcare consumers cope } \\
\text { with hidden aspects of 'life } \\
\text { after cancer' and adjust to a } \\
\text { new normal after illness is } \\
\text { 'cured', both inside and } \\
\text { outside of the healthcare } \\
\text { service setting }\end{array}$ & $\begin{array}{l}\text { Problematising } \\
\text { mainstream recovery } \\
\text { narratives }\end{array}$ & $\begin{array}{l}\text { Supplements traditional } \\
\text { recovery intervention } \\
\text { programs }\end{array}$ \\
\hline
\end{tabular}




\section{Procedural Disclosures and the Normalising Practice of Providing a Learning Resource}

Procedural disclosures of healthcare consumption experiences include the ways in which the healthcare system is conducted and experienced, offering more information about the hidden technical aspects involved in healthcare consumption such as drug treatments, medical procedures (e.g., surgeries), and medical devices in situ. In our data, women posted images, in real-time, of their ongoing healthcare treatments such as radiation, chemotherapy, and surgeries. Our data highlight how procedural disclosures drive the normalising practice of providing a learning resource. Yu et al. (2011) suggest that well-produced stories can offer valuable learning for others. In line with this, we contend that procedural disclosures via Instagram normalise critical information about hidden aspects of the healthcare consumption experience, thus serving as a useful learning resource for others who follow the visual story. For example, Carolyn posts images of herself receiving chemotherapy. In Figure 2, Carolyn describes the chemotherapy procedure, offering a first-hand account of her healthcare consumption experience.

Figure 2. Carolyn's Narration of Receiving a Chemotherapy Treatment Procedure 


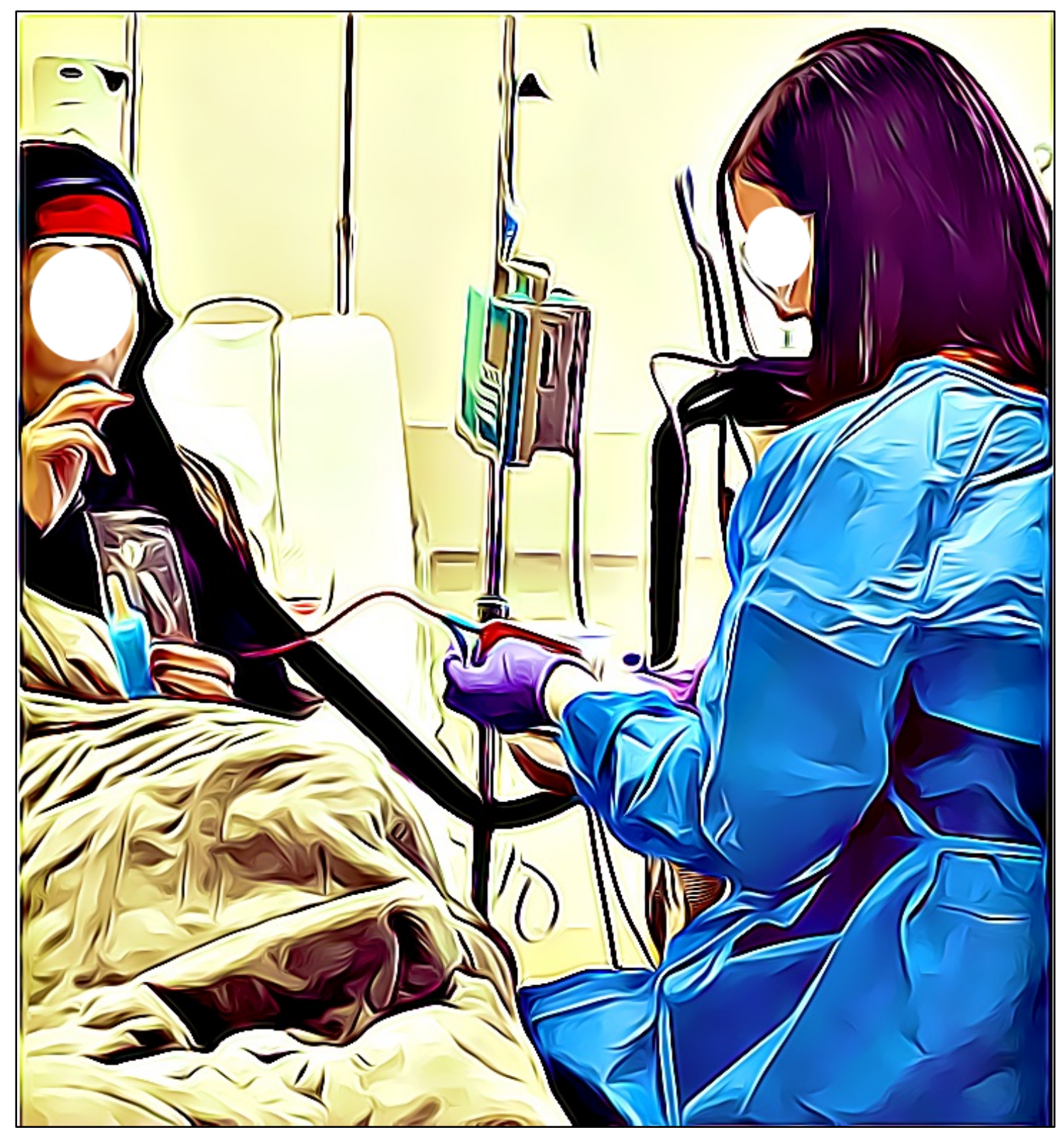

Carolyn's caption with Figure 2 [48 Likes; 20 Comments]: $A C$ chemo round \#2, day \#14. AC is the strongest form of chemotherapy known to mankind. The nurses wear protective gear to limit their exposure to the poison. Popsicles are served to patients during the infusion so sores/ulcers don't develop in the mouth as chemo doesn't just kill bad cells, but also the good. :- \#funfacts \#breastcancer \#breastcancersucks \#acchemotherapy \#chemotherapy \#meltingmytumor \#triplenegativebreastcancer \#Dignicap \#coldcaps \#coldcapssavedmyhair \#[deleted] \#mouthsores \#chemosideeffects \#cancer \#naptime \#breastcancerawareness @jenkinvillehospital

Carolyn's image and caption offer insider information about the chemotherapy process.

Furthermore, Carolyn's uploaded picture narrates the behind-the-scenes, often hidden experience 
of receiving treatment. The blue popsicle she is eating is not for pleasure; rather, it is a form of pain relief for the ulcers in her mouth resulting from the cancer treatment. Carolyn's post is educational (e.g., “chemo doesn't just kill bad cells”) for her followers and highlights potential gaps in their healthcare knowledge. In this way, Carolyn's image offers a visual learning resource of the embodied experience of chemotherapy- not just narrating but also visually representing to an audience her lived experience. Her healthcare providers are co-creators in constructing the image - her nurse is featured prominently and the Jenkinville Hospital, where Carolyn receives treatment is tagged in the caption (“@jenkinville”). Thus, consumers like Carolyn actively involve their healthcare providers in sharing procedural disclosures with a wider audience. Olsson and Lau (2015) highlight the fruitfulness of involving actors with varying areas of expertise to collaborate within the healthcare service system. Hence, the collaborative efforts in our study may signal important possibilities for information sharing in co-creating healthcare services. By using the digital affordances of Instagram (e.g., tagging, hashtagging), Carolyn narrates hidden aspects of her healthcare consumption experience to offer particular and nuanced learning resources for her audience. For example, AC chemotherapy is a powerful combination of drugs specifically used to treat breast cancer. Using the hashtag \#acchemotherapy offers more searchable detail to contextualise Carolyn's image and identifies the direct cause of her side effects, such as mouth sores which she also hashtags (e.g.., \#mouthsores, \#chemosideeffects).

In our data, procedural disclosures reflect healthcare consumption experiences that are sometimes even hidden from the patients themselves. That is, patients have procedures done to them and performed upon their bodies as the recipients of medical care; however, they are not granted a third person perspective of such procedures. Macy, who is undergoing radiation treatment, was curious to see what the process actually looks like, or as she says, she "wanted to know what they are doing to me." Macy posts a video to her Instagram page, narrating the radiation process, which she further narrates in her caption. The video, which is filmed by Macy's healthcare provider, shows the radiation machine (e.g., "pileup") circling slowly around her body.

\footnotetext{
Macy's caption posted with video [587 Views; 61 Likes; 4 Comments]: Radiation therapy number 14. Have you ever seen a radiation treatment? I hope not, but if you are as curious as I am, you may be interested. I asked the assistants if they could record me, because with the mask I do not see anything and I wanted to know what they are doing to me. They put the mask on me, raise the stretcher a lot and adjust the position, and
} 
then the pileup starts to spin. The video does not film when they radiate (has been cut $(-)$ ), but it is more or less the same adding a strong piiiiii that is repeated 5 times.

Macy's recording demonstrates an effort to gain control in a disempowered experience. Reflective of her vulnerability, Macy has little control over her cancer diagnosis, but she can control how much knowledge she has about the procedures. Although Macy's own curiosity prompted her to record the video, she chose to share a visual story of the procedure on Instagram - thus engaging in a normalising practice by offering a learning resource for followers and enabling them to see the radiation treatment for themselves. Like Carolyn, Macy's healthcare provider is actively involved in co-creating content to be shared to social media. This co-creation between Macy and her radiation specialist enhances the authenticity of the video, as it is filmed by a service provider who operates the machine regularly. The radiation specialist turned videographer has a deep understanding of the technical machinery movements and how to capture the process in a way that offers deeper and more accurate learning. Followers and other users browsing Instagram are then able to see and learn about the radiation experience through Macy's procedural disclosures, thereby normalising a hidden aspect of the healthcare consumption experience.

Image-based social media platforms offer a space for visual storytelling, by which procedural disclosures of hidden healthcare consumption experiences are narrated in real-time. Both Carolyn and Macy demonstrate how procedural disclosures normalise hidden aspects of the healthcare consumption experience by providing learning resources. Authentically pulling back the curtain demystifies often hidden procedures and presents them in easy to access snippets (e.g., 20-second autoplay video) on social media already embedded in consumers' daily lives, which has transformative potential for patient education and ownership in their treatment. In sharing these procedural disclosures, our data suggest patients and survivors engage in normalising practices by providing learning resources to a broad online audience. These visual stories offer an alternative form of education for followers and online users, who are given an insider view into how cancer is treated. Previous research suggests vulnerable healthcare consumers often turn to online sources such as WebMD for more information on medical procedures and treatments (Berland et al., 2001); however, from a visual storytelling perspective, our findings suggest Instagram offers a complementary and authentic digital learning resource 
through which followers can see the healthcare experience unfold from the patients' points of view, as co-created with healthcare providers.

\section{Corporeal Disclosures and the Normalising Practice of Cohering the Illness Experience}

Corporeal disclosures of healthcare experiences involve the ways in which vulnerable healthcare consumers experience and navigate hidden physical transformations that result from the consumption of healthcare services. Corporeal disclosures are particularly salient for women who experience breast cancer, as their physical bodies undergo drastic changes (e.g., weight loss, weight gain, loss of breast(s), loss of hair), particularly among young women (Fobair et al., 2006, Helms et al., 2008). Changes such as these are typically hidden from plain view in everyday life (Frith et al., 2007, Rosman, 2004); however, in our data, women use visual storytelling to normalise transforming bodies as they experience changes incrementally. Therefore, corporeal disclosures lead to the normalising practice of cohering the illness experience for vulnerable healthcare consumers. Given our study focuses on breast cancer patients' experiences, in particular, our data show many images of women's breasts as they experience bodily changes due to augmentation or mastectomy. However, these hidden healthcare experiences extend beyond breast related changes. In our data, women share visual stories of their transforming bodies, including skin rashes, scars, swelling, incisions, and bruising. In each case, women narrate their images through the digital affordances of captioning and hashtagging. Rather than 'before and after' images, these corporeal disclosures might be thought of as 'during' images showing the progression taking place from before to after, thereby normalising women's physical experiences with cancer treatments and the hidden transformations of their bodies. For instance, Lana, posts a video in which she proactively shaves her head. Lana suggests shaving her head allows her to claim hair loss as a choice, on her own terms, rather than waiting for chemotherapy to slowly cause her hair loss. In her caption, she notes this is "the moment when it all become real" and confesses to her followers, "I'm not always strong. and I want you to know my whole story, my highs and my lows." Lana's post points toward the value of visual storytelling and the need to share her story - both the positive and negative - with others. This reinforces the importance of digital networks for relating the personal and social aspects of breast cancer (Orgad 2007). 
Indeed, our data offer evidence of normalising both positive and negative hidden aspects of the healthcare consumption experience as women's bodies physically transform throughout their cancer treatment. For example, in a series of four images, Theresa narrates her ongoing hair loss following chemotherapy and her hair regrowth in recovery. In addition to her hair loss and regrowth, she notices changes in her facial appearance (e.g., "hamster steroid cheeks") and other hair changes (e.g., lashes, brows).

\section{Theresa's caption posted with images of hair growth [45 Likes; 2 Comments]: \\ Hard to believe this was two whole years ago bec... since I was an egg head $\mathbf{Q}$, since I was Fester-, since I was fighting to be alive I still have my hamster steroid cheeks, I now have my own brows and lashes back again, and of course I've got my beloved curls \#nevertooyoung \#cancerisntpicky \#checkyourself \#selfawareness \#stopthefight \#cancerwarrior \#chemocurls \#twoyearson \#thebattleneverends \#onedaynoonewillhavetofight \#baldie \#egghead \#cancersucks \#lifechangingmoments \#livinglife \#withmycurls \#curlsforgirls \#curlyhair \#baldhead \#fester \#cancerawareness}

Theresa's comparison to her bald-self as an "egg head" and "Fester" are critical terms of endearment, coupled with symbolic emojis. Particularly in cases of women's bodies, humour is used to destigmatise bodies that misalign with the cultural expectations of what is considered ideal (Singh, 2018). Similarly, Theresa's nicknames (e.g., egg head, Fester) and emojis (e.g., egg in frying pan, bald man) signal humour used to help destigmatise and therefore normalise her hair loss and facial changes that stand in opposition to dominant feminine cultural ideals (e.g., desirable long hair, prominent cheekbones, long eyelashes). Theresa's corporeal disclosures offer followers a visual story narrating the experience of losing and regrowing hair as a woman after cancer treatment. Hair loss, particularly among female cancer patients, is typically hidden from the public, as women may opt for wigs, hats, or headscarves to hide the changes in their hair (Frith et al., 2007, Taggart et al., 2009). In contrast, Theresa's Instagram profile provides a detailed narration of her ongoing hair loss and hair growth, thus demonstrating the normalising practice of cohering the illness experience. Theresa uses hashtags like \#curlsforgirls, \#curlyhair, and \#withmycurls, alluding to the fact that patients' hair often grows back curly following cancer treatment. In fact, across our data, including in Theresa's other posts, women refer to this phenomenon as "chemo curls". Theresa's "beloved curls" are a bright spot in her ongoing experience with cancer and serve as a physical, bodily symbol of recovery. In the healthcare service setting, vulnerable consumers are sometimes provided with visual decision aids offering 'after' images of medical procedures (e.g., breast reconstruction, skin damage after radiation), 
yet such photographic decision aids are limited in "the complexity of distribution, the need to tailor information to local practice, and the need to update them as new information becomes available" (Sawka et al., 1998). To that end, our findings suggest image-based social media may supplement healthcare services by providing comprehensive, customised, and immediately available content for vulnerable healthcare consumers to draw upon in healthcare decisionmaking.

Our data demonstrate the role of visual storytelling in normalising hidden physical transformations through corporeal disclosures by vulnerable healthcare consumers. Women in our study narrate their experiences with losing tangible pieces of the body (e.g., hair, breasts), which are deeply embedded in cultural ideals of what it means to be a woman (Helms et al., 2008). In Theresa's case, all of her hair loss and regrowth images are selfies, suggesting she is taking ownership of her story to share with others. Sharing the incremental transformations of this through visual storytelling - as opposed to presenting 'before and after' images - works to normalise the process by which her appearance has changed, thus cohering the illness experience. Narrating the incremental physical evolution of one's body is consistent across our data. For instance, Molly chronicles incremental corporeal changes in her body throughout treatment and recovery - most prominently, the physical evolution of her breasts. As shown in Figure 3, Molly offers an ongoing series of images and videos on her Instagram profile narrating her double mastectomy and breast reconstruction. 
December 14, 2016

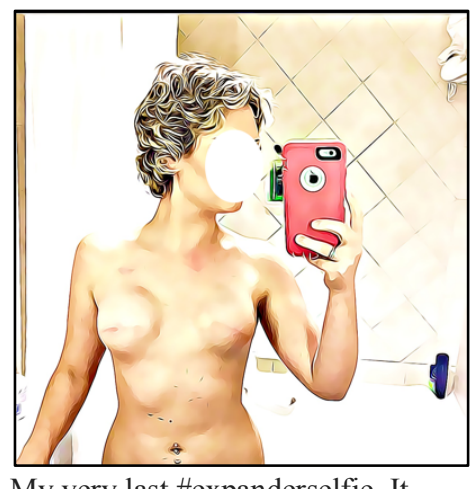

My very last \#expanderselfie. It just hit me that this is the 2nd time in my life that my body will be changed forever. By lunch time I should have my forever \#foobies and I am so relieved! I cannot wait to get these rocks out and jiggly titties in! I have my fingers crossed that I come out looking like

Barbie! \#breastcancerselfie

\#breastcancer \#boobies

\#breastcancerawareness

\#breastreconstruction

\#doublemastectomy \#chemocurls
December 15, 2016

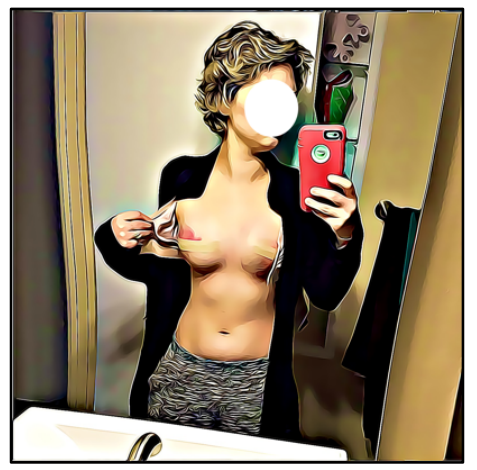

Day 1 of breast reconstruction. Very sore and bruised. I received $470 \mathrm{cc}$ gummy implants around 930am 12/15/16. Once the swelling goes down a little hopefully they look more boobish;) \#breastcancerselfie \#breastcancer \#boobies \#breastcancerawarenes \#breastreconstruction

\#doublemastectomy \#chemocurls \#gummyimplants \#470cc
December 16, 2016

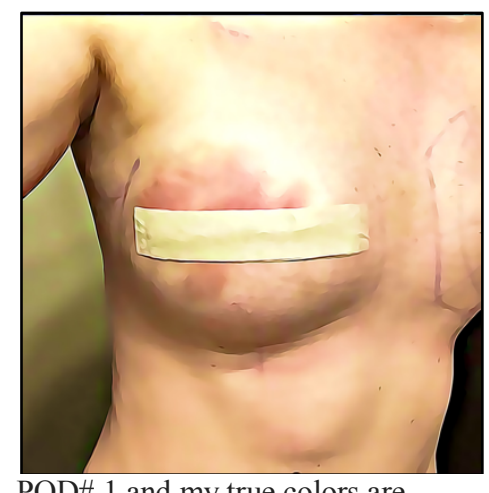

POD\# 1 and my true colors are shining \#breastcancerselfie \#breastcancer \#boobies \#breastcancerawareness \#breastreconstruction

\#doublemastectomy \#chemocurls \#gummyimplants \#470cc
December 20, 2016

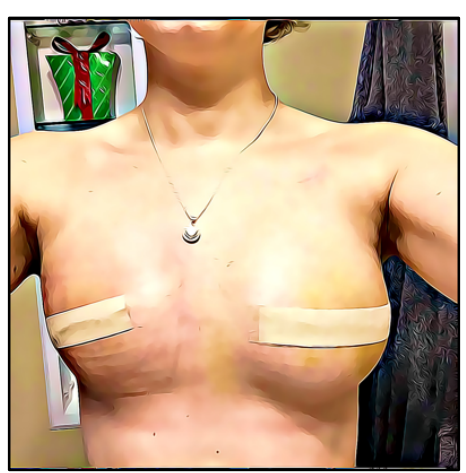

POD \#5 and you realize your boobs may be a little wonky:( $i$ an hoping and praying it has to do with my surgeon having to do more work on the right (cancerous / radiated) side, however the bruising is lightening and im just thankful to have some titties! Its a little embarrassing sharing a

maybe crooked boob job

however this is a reminder that post mastectomy foobies are always different and more complicated than normal barbie girl elective boob jobs! I am rathe excited for some perfectly round, full foobies though! Crooked or not!;) my surgeon kicked butt! \#breastcancerselfie \#breastcance \#boobies \#breastcancerawareness \#breastreconstruction

\#doublemastectomy \#chemocurls \#gummyimplants \#470cc \#boobjob \#mastectomy \#bilateralmastectomy
December 27, 2016

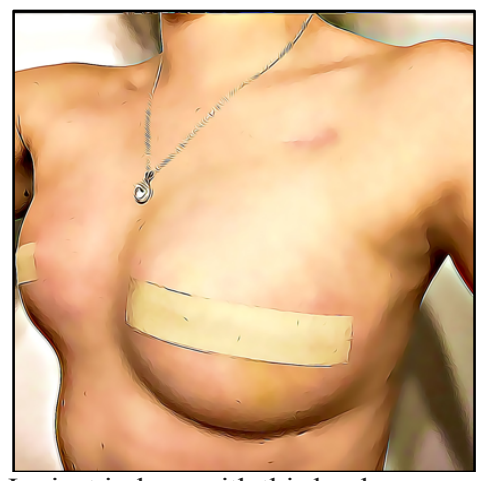

Im just in love with this boob, almost two weeks post breast reconstruction (double mastectomy in april) look, $i$ actually have boooooobs! My cancer sisters will get my excitement! \#itsabigdea \#sorrynotsorry \#stillbruised \#motorboat \#ifinallyhaveboobs \#otheroneneedswork

\#atleastihaveone

\#breastcancerselfie \#breastcancer \#boobies \#breastcancerawareness \#breastreconstruction

\#doublemastectomy \#chemocurls \#sparkleon \#gummyimplants \#470cc \#boobjob \#mastectomy \#bilateralmastectomy \#port \#portscar\#foobies \#workofart 
Molly offers behind the scenes, real-time corporeal disclosures narrating how her physical appearance is transforming. The images and captions shown in Figure 3 begin on the day of her breast reconstruction surgery and span two weeks post-operation. In this way, Molly engages in visual storytelling as the story itself unfolds - rather than retrospective accounts. For her Instagram audience, she discloses the incremental corporeal changes taking place as well as her emotional reflections at each point in time. Molly's references to her service provider (e.g., surgeon) reflect how healthcare consumption experiences are mediated through Instagram, as Molly narrates her triumphs and disappointments. For instance, in Molly's post on December 27, 2016, she offers the following hashtags to express her simultaneous joy and disappointment: “\#ifinallyhaveboobs \#otheroneneedswork \#atleastihaveone." In the case of cancer, aesthetic appearance concerns may be perceived as vain or inconsequential relative to surviving the disease itself. However, our data consistently show corporeal disclosures are central to women's experiences with cancer and by sharing visual stories of physical change on Instagram, patients and survivors are able to cohere the illness experience and normalise bodily transformations as they unfold. By visually narrating incremental body transformations that occur throughout the healthcare experience, vulnerable healthcare consumers challenge the embodied simplicity of the 'before and after' narrative and normalise their evolving bodies. Consequently, these corporeal disclosures cohere the illness experience for followers, who are able to follow the detailed and ongoing transformation of women's bodies. Breast cancer patients and survivors have historically been expected to remain silent and keep their wounds hidden (Datan, 1989). Wilkinson (2001) asserts women with breast cancer are culturally compelled toward concealment - to hide the visual evidence of their illness (e.g., surgical scars, flat chest following mastectomy) and to maintain outward appearances in line with feminine body ideals - and concludes "unless and until women with breast cancer can freely 'show and tell' their experience, it will remain a solitary ordeal, rather than an issue to be 'owned' and addressed by the community at large" (p. 273). Our data, in contrast, suggests image-based social media provides transformative potential for bolstering women's voices and bodily changes. To that end, our findings suggest visual storytelling on social media has ushered in a turning point in how vulnerable healthcare consumers normalise the often hidden physical transformations as a result of healthcare consumption experiences and cohere the illness experience itself. Once perceived as taboo, medicalised bodies are normalised and even celebrated on image-based social media through corporeal disclosures. 
Recovery Disclosures and the Normalising Practice of Problematising Mainstream Recovery Narratives

Recovery disclosures include the ways in which vulnerable healthcare consumers cope with hidden aspects of 'life after cancer' and adjust to a new normal after illness is 'cured', both inside and outside of the healthcare service setting — in this case, following a mastectomy or after being deemed "cancer free." The challenges of adapting to a new normal are well-documented in healthcare literature; however, women report feeling diminished support from healthcare service providers and reticence to discuss concerns with close friends or family for fear of worrying them (Allen et al., 2009). Our data suggest recovery disclosures lead to the normalising practice of problematising mainstream recovery narratives, which function under the assumption that once the cancer is 'cured' or 'gone' life continues as normal. Breast cancer survivors in our data show how their healthcare experiences with cancer continue to influence their lives as they adjust to a new normal—normalising the ongoing emotional and lifestyle transformations that continue after cancer is 'cured'. For instance, Lana is a 23-year-old breast cancer survivor who used Instagram to narrate her cancer journey while in treatment. Now in remission, Lana continues to use the social media platform to share ongoing recovery disclosures. In Figure 4, Lana shares an experience from one of her monthly follow-up visits to the hospital. 
Figure 4. Lana Narrating 'Life After Cancer'

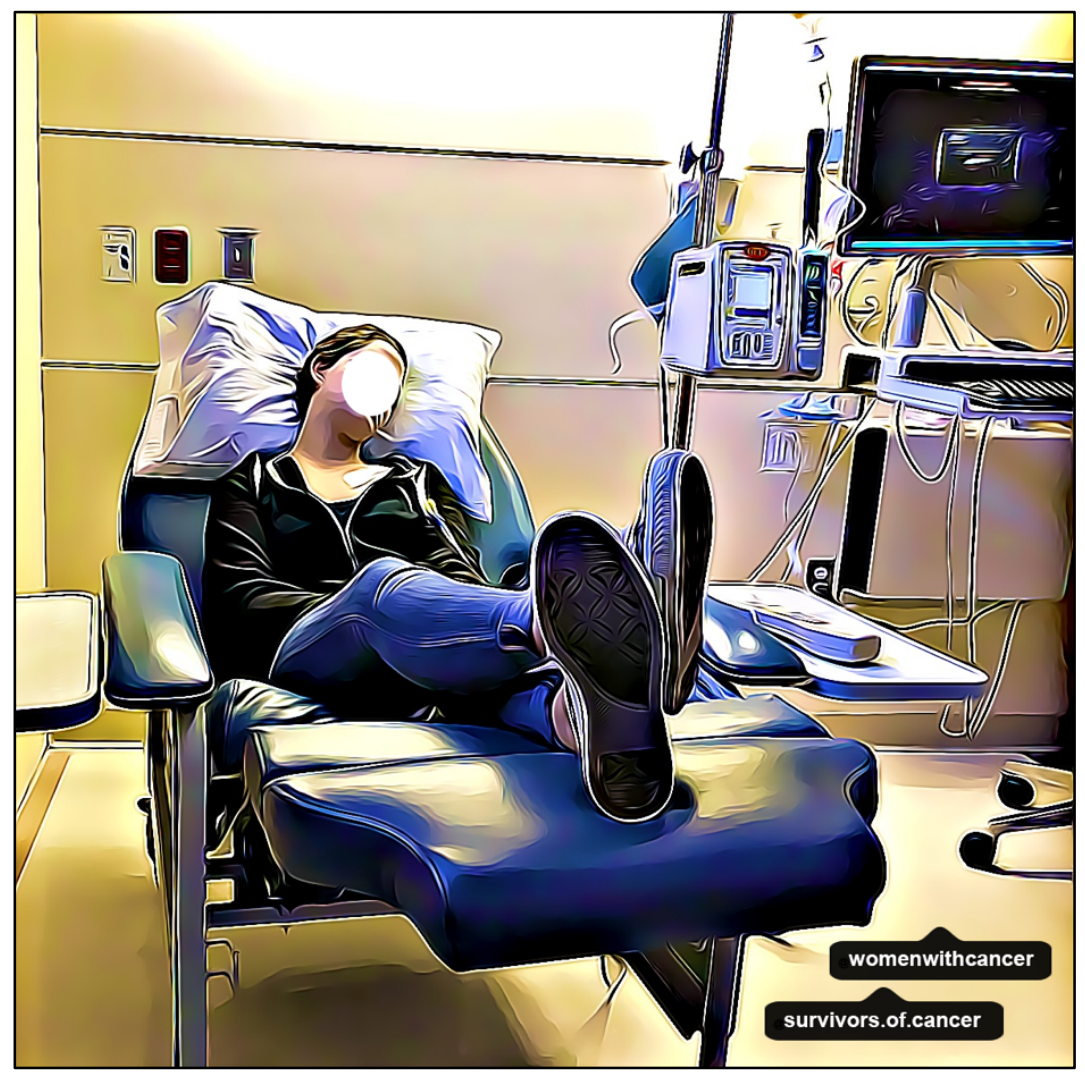

Lana's caption with Figure 4 [393 Likes; 58 Comments]: well yesterday I went in for my monthly follow up and my fear came true. I ended up in that stupid chair. my iron level is low and they wanted to give me iron and fluids. I have such anxiety thinking about being in that chair. thankfully once it started going I was able to rest. unfortunately I'll still be needing more iron infusions but I can at least now prepare myself. people think once you're done with treatment and cancer free, it's all over. sadly, that isn't the case but this is life after cancer and it's just another bump in the road. Gods got me.

\#breastcancer \#breastcancerawareness \#cancersucks \#survivor \#chemotherapysucks \#staypositive \#mystory \#breastcancersurvivor \#chemosucks @stupidcancer@weare.survivors@fightlikeawarrior \#youngcancersurvivor \#cancersucks \#radiationsucks \#triplenegativebreastcancersurvivor \#lifeaftercancer

Despite no longer 'having' cancer, Lana must continue to navigate the healthcare service system and the mental and physical repercussions of her illness. She expresses anxiety surrounding the particular chair used for infusions and outpatient treatments to boost her iron levels. These mental stresses are not readily visible, but in our data, survivors like Lana express ongoing health-related concerns and fears. Most notably, the ever-present possibility 
of relapse, or that the cancer may return. Lana's health is precarious, despite being in remission, and this uncertainty weighs heavily on her. As Lana notes, there is a cultural perception that once cancer treatment has ended and a person is deemed 'cancer free,' then the hard part is over. In reality, recovery brings with it a new and often undiscussed set of challenges (Allen et al., 2009, Langellier and Sullivan, 1998) - fears of relapse, adjustment to one's new body, modifications to diet or exercise routine, impact on personal relationships (e.g., marriage, children) or belief systems (e.g., faith), among others. Recovery disclosures, like Lana's, serve to normalise these fears and problematise mainstream recovery narratives. From a physical perspective, Lana demonstrates the ongoing care her body requires, such as monthly check-ups and potential treatments (e.g., iron infusion). Lana uses tags and hashtags to narrate a 'life after cancer.' In Lana's image, she tags two other Instagram accounts, @womenwithcancer and @survivors.of.cancer. Both accounts compile images and inspiration from women who are in recovery, thus aggregating recovery disclosures. By tagging these accounts, Lana signals membership in these groups and offers her image to be shared more broadly as part of a collective visual story for followers to view beyond her individual profile. These stories come together to normalise a more nuanced understanding of how women adapt to life once their cancer is 'cured', thus problematising mainstream recovery narratives. The mainstream perception of life after cancer is women should be positive and grateful for their survival; however, this narrative overlooks the ongoing recovery struggles women face (Kaiser, 2008). Although Lana's caption ends on an optimistic note, her hashtags reinforce the angst she feels toward cancer, including hashtags like \#chemosucks, \#radiationsucks, and \#cancersucks. Lana, like other survivors, does not want to return to a life with cancer and uses Instagram to share her fears of that possibility. Our findings support early work suggesting the Internet might be a transformative space for breast cancer patients to communicate (Orgad, 2005); however also demonstrate how visual stories of hidden healthcare consumption experiences are central to creating a more nuanced understanding of recoveryproblematising mainstream recovery narratives and normalising the real struggles women continue to face. Previous work suggests women "may need additional skills in eliciting social support from their networks, as well as increased opportunities for providing support to others" as they transition from breast cancer 'patient' to breast cancer 'survivor' (Allen et al., 2009). Our study highlights how Instagram provides an outlet for women in recovery to visually narrate their experiences for a broad audience - thus supplementing face-to-face networks (e.g., healthcare service providers). 
Lana's experience is repeatedly echoed throughout our data as women transition into recovery. They use Instagram to normalise ongoing emotional and physical recovery following cancer. While Lana's experience relates directly to the fears associated with relapse, other women share recovery disclosures related to more everyday activities. For instance, prior to her breast cancer diagnosis, Julia competed in physical fitness competitions, and her physical competence was central to her identity. Julia posts a video of herself doing a pull-up at the gym and reflects on adapting to a new normal related to exercise.

\begin{abstract}
Julia's caption posted with exercise video [797 Views; 217 Likes; 20
Comments]: Probably the MOST SCARED I have ever been to do an assisted pull-up. If you know me... Back day was MY FAVORITE DAY! And I use to CRUSH IT! After a year of the most intense chemotherapy and radiation therapy.... oh yea and a DOUBLE MASTECTOMY with reconstruction (nothing major (-)) I am back in the gym, however everything is TERRIFYING. My body IS NOT THE SAME. I have to take things EXTREMELY SLOW, and that for me is ridiculously FRUSTRATING. But I try to remember I am where I am BECAUSE OF MY STRENGTH and my FAITH. Today was a HUGE VICTORY IN THE GYM. [...] \#lifeaftercancer \#breastcancersurvivor \#thriver
\end{abstract}

Weightlifting, which was an enjoyable activity for Julia, is now a bittersweet source of both accomplishment and anxiety in recovery. Julia's video shows her actively grappling with her fears and frustrations. In a separate Instagram post, Julia writes, "Most people think when you beat cancer life goes back to normal and the survivor gets to move on with this new found spirit for living and for life. Truth is when treatment is all done [...] the survivor is still standing there alone looking in the mirror with a beat up body not quite sure who they are and what they have become." Julia's exercise video reflects her perceived "beat up body" and visually narrates a personally significant milestone as she adapts to her new normal. More importantly, Julia's visual story gives her social media followers insight into the embodied world of recovery and normalises the ongoing challenges breast cancer survivors face as they complete tasks and activities which once were simple or ordinary. Indeed, breast cancer can affect women's sexuality, sexual health, and body image for years after successful treatment (Emilee et al., 2010, Pelusi, 2006). Other women visually narrate challenges related to everyday activities, such as caring for children, going on dates, engaging in sexual intimacy, and returning to work. Thus, recovery disclosures problematise mainstream recovery narratives, which suggest women can easily return to their pre-cancer lifestyles beyond the healthcare service setting.

Our findings offer evidence of how women grapple with and in turn normalise lifestyle issues in a very public and visible way. Previous research recommends health service 
providers should "continue to ask survivors about alterations in body image and sexuality even after treatment is over" (Pelusi, 2006). While valuable, these discussions are privy only to the patients and clinicians involved. In contrast, our findings suggest women's visual stories of recovery shared on Instagram offer an opportunity to normalise the struggles and triumphs women face as they adapt to a new normal. Breast cancer takes a physical and emotional toll on the body, which can make pre-cancer tasks more challenging and frustrating. Clinical healthcare service research suggests interventions, such as support group participation and individually tailored programs, can reduce cancer survivors' recoveryrelated stressors (e.g., body image concerns, PTSD, sexual functioning, fatigue, cognitive functioning); however, such interventions may be limited by factors such as geographic location, social stigma for seeking help, and insurance costs (Alfano and Rowland, 2006). Women in our data share visual stories of recovery, comparing pre-cancer and post-cancer selves not only from the perspective of medical health, but also how cancer continues to affect their everyday lives (e.g., exercise, intimacy, work performance, social relationships). These stories are widely available, free, and anonymous to browse on image-based social media; thus, supplementing traditional interventions offered by healthcare service providers. Our findings suggest visual storytelling on Instagram offers transformative potential by allowing women to narrate the hidden everyday challenges and triumphs they continue to experience in recovery and problematising mainstream recovery narratives. Julia and Lana both employ hashtags, such as \#lifeaftercancer and \#breastcancersurvivor. These digital affordances enable normalisation of hidden healthcare consumption experiences by making the visual stories more discoverable for those interested in 'life after cancer.' Recovery disclosures, as Lana and Julia demonstrate, problematise mainstream recovery narratives that the hard part is 'over' once treatment is completed. Visual stories shared through digital media show how breast cancer survivors adapt to a new normal, including how they negotiate the culturally abject body and challenge dominant cultural narratives of life after breast cancer.

\section{Social Support for Vulnerable Healthcare Consumers}

As healthcare disclosures are shared through visual stories on Instagram, hidden healthcare consumption experiences become normalised. Through this, vulnerable healthcare consumers and other Instagram users are able to connect enabled by digital affordances (e.g., commenting, liking, hashtagging) on the platform. Instagram provides a unique space for social support given its ability to form deeply connected relationships through real-time 
interactions. In contrast to message boards (Meric et al., 2002) or blogs (Kim, 2009), Instagram is embedded in consumers' lives on a daily basis. Thus, in the case of breast cancer patients and survivors, their experiences are not quarantined to corners of the internet. Instead, they readily and easily form connections through a social media platform already in use in their lives. Image-based platforms such as Instagram enhance intimacy among users and decrease loneliness more than text-based platforms (Pittman and Reich, 2016). Additionally, the ability to easily comment and interact via Instagram allows women to ask questions, offer advice, share encouragement, and more in real-time, in line with previous work which suggests social interaction is a key motivator for using Instagram (Lee et al., 2015). Specifically, our data suggest visual storytelling on Instagram normalises hidden aspects of healthcare consumption experience for vulnerable heathcare consumers, which in turn fosters two types of social support: informational support and companionship support.

\section{Informational Support}

In our data, vulnerable healthcare consumers provide detailed informational support to one another as it relates to breast cancer. Informational support provides detail for how to navigate the healthcare consumption experience, such as how to have conversations with doctors or where to seek ideal products for recovery. For example, Carolyn offers product suggestions such as hair regrowth treatments, special pillows to reduce swelling after mastectomy, and particular bras that are considered more comfortable. Carolyn even details the type of implants she received - including the specific brand. These peer-to-peer recommendations provide informational support for women as they seek remedies and relief, perhaps not readily available in the healthcare services setting. More notably, Carolyn engages with her followers to provide more details regarding her trial-and-error process for discovering preferred products or discussing healthcare with her doctor. Carolyn posts a series of three images documenting her breast reconstruction surgery and narrating her experience.

\footnotetext{
Carolyn's caption posted with breast reconstruction images [218 Likes; 78

Comments]: Before my mastectomy I had major anxiety about what to expect in terms of results. My anxiety was so bad, that a few days before I considered cancelling the surgery. I wanted to jump on a plane and fly to a tropical destination and pretend like breast cancer wasn't my reality. Luckily, two brave women that I had been introduced to through friends, shared their surgical results with me. After seeing their breasts, I felt 100\% at ease with proceeding with surgery and I'm SO grateful for them, words can't explain. In fact, I even showed pictures of a few of my fellow IG breasties and their results to my surgeon, asking for their same implants. So now I'm doing the same, I'm sharing pictures of my breasts so other women can get an idea of what to expect. I had a
} 
nipple sparing bilateral mastectomy with incisions at the bottom of the breasts. In the first picture my natural breasts are shown in a bathing suit, followed by expanders and then my final implants. The 2 nd and $3 r d$ pictures are my implants [...]. My implants are smooth round Natrelle Inspira SRX. Everyone's results vary and in my opinion none are perfect when compared to a traditional breast augmentation. But by sharing our results, we can help each other have realistic expectations. I know a few of you ladies have your surgery coming up, so I hope this helps ease your mind. \#breastreconstruction \#thisisbreastcancer \#bravewomen \#breastcancer \#breastimplants \#inspiraimplants \#natrelleinspira \#bilateralmastectomy \#mastectomy \#beforeandafter \#tissueexpanders \#nipplesparingmastectomy \#implantexchange \#johnshopkinsplasticsurgery \#johnshopkins \#youngwomenwithbreastcancer @hopkinsplasticsurgery

In line with procedural disclosures, Carolyn's Instagram post normalises hidden technical aspects of the healthcare consumption experience by providing a learning resource for followers, such as offering suggestions for navigating conversations with doctors and specific product recommendations. Carolyn identifies her breast implants as Natrelle Inspira SRX and suggests others can use her images as a guideline for recovery - to an extent. By posting her own pictures and her experience, only two weeks post-surgery, Carolyn aims to help other women with breast cancer manage their expectations of what may be realistic, in line with the corporeal and recovery disclosures of the healthcare consumption experience. Carolyn's post, which garnered over 100 comments, offers informational social support to her fellow Instagram users. Carolyn responds to enquiries, offering more details about her personal experience. For example, a follower, Eileen, comments that she recently underwent a bilateral nipple sparing mastectomy, and on the way home from surgery, she comments on Carolyn's image. Carolyn responds in real-time.

Eileen's Comment: Thank you [for sharing]! Just driving home from my bilateral nipple sparing mastectomy. 6 hours home, spent two night in the hospital, Still working on the best pain control. So feeling a little high right now! They found micro matastasies in first node so 6 were taken and were clear. Hopefully no radiation needed. So here are my question $s$ I was a B before nursing two babies then an A before surgery on Tuesday. What should I go for on size? How many cc added at a time, are yours under muscle? Mine are ... any other suggestions??

Carolyn's Response: My size was determined by my surgeon. She said my pocket measurements determine my size. However, I know what I wanted and in the end we agreed on size. I also showed her pics of breasts I liked and she said she would try to achieve that for me. CC can be the same on two different women but look completely different based on measurements. She added different amounts of cc each time based on how my skin was stretching. I had my implants placed under the muscle. I've heard there is less rippling that way. Good luck with everything! Hoping you're healing well! 
In Carolyn's original post, she strategically uses niche hashtags to connect with others who may be seeking similar information. For instance, \#nipplesparingmastectomy is a unique type of surgery. By clicking on the hashtag, consumers who also have undergone or may be planning a nipple sparing mastectomy can discover Carolyn's post. Eileen sees Carolyn's post when she is on her way home from her own nipple sparing surgery. Presumably, breast reconstruction is top of mind for Eileen. Her and Carolyn's interaction reflects the type of intimacy that can occur through a digital space (Lomanowska and Guitton, 2016). Indeed, vulnerable healthcare consumers are increasingly willing to disclose personal details of their lives via the internet, and this level of online intimacy and social support can enhance consumer well-being (Chuang and Yang, 2010). The feedback Carolyn provides is fundamentally different than asking a doctor. Eileen is able to connect with someone else's lived experience through Instagram and views Carolyn as a trusted ally and advisor. Notably, the real-time nature of the interaction is unique to the Instagram platform, versus waiting for a doctor's advice or posting on a message board. Carolyn and Eileen's exchange is representative of interactions we see throughout our data, as women connect with one another through Instagram. The immediacy of the interaction adds authenticity to the experience. Moreover, other women can view the exchange publicly. It is not a private conversation offline or over email. Therefore, the comment section on the post becomes an archive of informational support as other women can return to the conversation and learn from it as well.

Informational support is also enabled as women share and seek best practices (e.g., athome treatments, preferred products). This is a two-way interaction in which women offer advice to others and/or actively solicit advice from followers. For example, Sara, shown in Figure 5, offers a visual image of her prosthetic breast piece, which she recommends to followers.

Figure 5. Sara's Narration of Using a Prosthetic to Correct Breast Asymmetry 


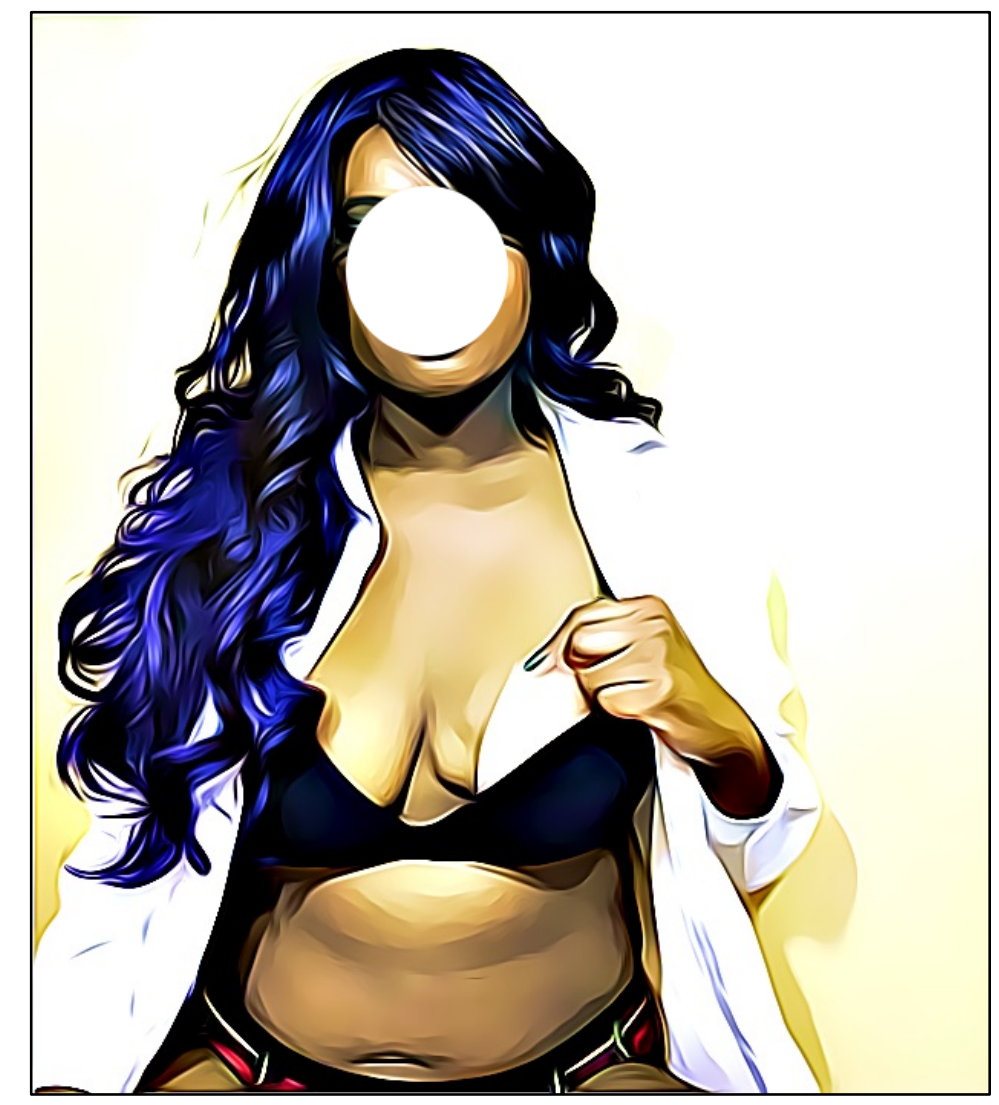

\begin{abstract}
Sara's caption with Figure 5 [165 Likes; 15 Comments]: Honesty Is The Best Policy:: Someone was confused about why my breasts look symmetrical in some pictures and not in others. I use this prosthetic piece. I got it from@amazon. It's not perfect symmetry, but it helps. If there are any women who would like a prosthetic piece, cross dressing men, or t-gurls, I'd recommend checking Amazon for prosthetic breasts and bras. They feel real and they're cheaper on Amazon than anything I've found anywhere else. I hope this helps someone! $\bigcirc . . .$. \#bodypositive \#curves \#daremagazine \#effyourbeautystandards \#fashionblogger \#fatshion \#plus_isamust \#allsizebeauties \#boldncurvy \#plusmodel \#whatfatgirlsactuallywear \#plusmodelmag \#plussize \#plussizeblogger \#plussizefashion \#thickgirlzrock \#instagood \#picoftheday \#fashion \#style \#ootd \#psootd \#inspiration \#weheartit \#ic360curvypic \#winter
\end{abstract}

In line with corporeal and procedural disclosures, Sara's post narrates her hidden secret of using a prosthetic to correct asymmetry of her breast, thus normalising the use of the product itself and the appearance of post-cancer body. Sara's image provides a compelling, authentic form of informational support - not just saying she uses the prosthetic but actually showing the product in use. Sara's hashtags, interestingly, have no mention of cancer or breast cancer. Instead, she signals her membership in the fashion community through fashion related hashtags. Sara is a plus-size model and fashion blogger, who also happens to be a breast cancer survivor - reflecting how recovery disclosures work to problematise mainstream recovery narratives. Being a plus-size woman is already perceived as contradictory to 
mainstream beauty ideals, so to add breast asymmetry further deepens the challenges Sara faces in the fashion and beauty marketplace. Sara uses hashtags like \#effyourbeautystandards and \#bodypositive to signal a rebuking of mainstream beauty expectations; yet, at the same time, she offers advice on how to conform to such expected standards (e.g., symmetrical breasts). This push and pull of conforming to beauty standards while also challenging them is a consistent theme in our data. Women desire to be comfortable in their own skin, but are constantly reminded by culture that their bodies are abnormal. By Sara embracing fashion modelling and blogging, she is able to share her story with a wider audience beyond cancer survivors. For example, several of the comments on Sara's image are from users whose mothers have experienced breast cancer. Thus, the network of social support extends beyond only cancer patients. As a function of the digital affordances of Instagram, the social support network expands to include friends and families of cancer patients. For instance, Sara's image garnered the following exchange in the comments section.

Taki: Omg my mom just had surgery to remove her breast because of breast cancer and I've been looking for her some! (0) you're a life saver!

Sara: I'm so happy I could help!

Sara's post provided informational support beyond direct patient-to-patient interaction. Previous research suggests when family members better understand breast cancer (e.g., treatments, symptom management), patients are significantly more hopeful and positive (Northouse et al., 2002). Our findings suggest visual storytelling on Instagram can educate family and friends about hidden aspects of healthcare consumption experiences, thus potentially better supporting their loved ones.

In some cases, women use their Instagram profiles to actively seek advice from followers. For instance, Karen posts an image of cording in her arm, in which the tissue becomes painful and taut as a result of lumpectomy or mastectomy. Karen's post reflects corporeal and procedural disclosures, as she navigates physical transformations of her body and seeks advice for coping with the pain.

\footnotetext{
Karen's caption posted with image of cording [104 Likes; 23 Comments]: Question for my breasties.... did you experience cording in your arm after surgery or treatments and what tips/tricks do you have to help relieve it? I've been getting cording on and off in my right arm ever since I finished radiation and have been stretching my arm and getting my husband to massage it but it's not letting up this time. Help! \#breastcancer \#breasties \#pinksisters \#pinklife \#breastcancerawareness \#cancersurvivor \#cording \#cancerscars \#cancerwarrior \#pinkwarrior \#myscarsarebeautiful
}

Karen directly addresses her followers as "breasties" - a term we see often in our data. Breasties is a mashup nickname combining 'breast' with 'besties.' Karen's use of "breasties" 
in her post signals she is a member of this subculture and calls upon other women who identify as "breasties" to answer her question. Karen's post reflects the fundamental differences between Instagram and other platforms or traditional support groups, including the real-time nature of the information exchange (versus an in-person support group) and the very niche audience one might reach (versus a broad social network like Facebook). Karen's \#pinksisters, as she refers to them in her hashtags, respond with an array of detailed recommendations, demonstrated by a few selected comments below.

Brenn: do your physio exercises that they gave you to do after your surgery. I do mine everyday on the regular and it helps stretch it out.

Helen: Have it too! Need to stretch and exercise it everyday!!

Tonya: Yoga has helped me immensely

Jane: Yes.... went to physical therapy, stretches geared to the affected area, self massages with shea butter, lymphatic massages with a specialist trained in the technique

Importantly, the informational support (e.g., advice for best practices) is coupled with a shared sense of community. Women who comment on Karen's post are most often women who have first-hand experience with cording, a very specific ailment related to breast cancer. The underlying theme in all of the comments is: I understand what you are going through and we are in this together-which can be transformative for women as they seek empathy and connection. Thus, the informational support is coupled with companionship support, which we will discuss further in the next section.

\section{Companionship Support}

Our data show how social media facilitates companionship support among women who are undergoing treatment for breast cancer. As discussed in the previous sections, visual storytelling on social media allows vulnerable healthcare consumers to normalise hidden aspects of healthcare consumption experiences. In turn, they share companionship support as they bond over similar normalising experiences, drawing upon Instagram's digital affordances (e.g., following, commenting) to connect with others. Through features like hashtags and comments, Instagram users are able to form a deep sense of community, as evident in references to the "breasties." A key component of companionship support facilitated through Instagram is the customisable nature of it. Women are able to find others who have extremely niche, similar experiences, thus debunking the idea that breast cancer is a one-size-fits-all experience. Our data show women around the world connecting with one another through frequently used, niche hashtags such as \#triplenegativebreastcancer and \#nipplesparingmastectomy. The ability to seek out such support and receive immediate real- 
time connections from others who closely align with one's own personal experience is unique to the nature social media. For example, Alyson posts an image of her chest and comments on the unevenness of her breasts.

\begin{abstract}
Alyson's caption, posted with image of asymmetrical breasts [138 Likes; 14
Comments]: I noticed today that my breasts are noticeably more uneven. NOPE.. $i$ refuse to give into vanity and complain. I wanted to.. $i$ wanted to stand in the mirror and pick apart what didn't look "normal," but no. That's not me. For goodness sake, they took the cancer out of me and I am alive another day. So, instead $i$ will be grateful, walk taller. This too is a badge of what $i$ went through and i promise to wear it with honor. Don't worry, if you are getting a mastectomy and feel like you're going to look uneven, expanders are just the rough draft - For now $i$ will think of myself like i'm a walking Picasso. .. \#asymmetricalboobs \#pablopicasso
\end{abstract}

A follower, Kim, commented on Alyson's image, noting her own similar experience:

Kim: Yes !!!!! My expanders weren't even either -3 alf the time I didn't notice until I saw a pic 2 haha. They even put eventually, especially after exchange. Heck I'm just enjoying no bra U'Mou got this beautiful

Alyson and Kim are able to develop companionship supported by the digital affordances of Instagram. Their shared experience is not around having expanders but around the much more nuanced experience of having uneven expanders, further reflecting how corporeal disclosures work to normalise hidden aspects of the healthcare consumption experience by cohering the illness experience. Alyson even hashtags her image "\#assymmetricalboobs" offering a searchable way for others to find her post and connect over this very specific consequence of breast reconstruction. As Alyson and Kim demonstrate, breast cancer survivors can immediately connect with others in their shared network and feel solidarity in their normalised experiences with healthcare consumption, outside of the realm of a formal 'support group' or institutionalised setting. Thus, women in the online breast cancer community on social media connect broadly as breast cancer survivors but then take those connections deeper as they form bonds over very specific shared experiences. The nuance in the breast cancer community is able to emerge through Instagram, as each woman can share her individual story and offer companionship support to one another.

Many women in our data chose to undergo breast reconstruction; however, Gigi is unique in her decision to remain "flat" after double mastectomy. Shown in Figure 6, Gigi offers evidence of being 'breastless' and narrates how her experience is unique.

Figure 6. Gigi's Narration of Remaining 'Breastless' 


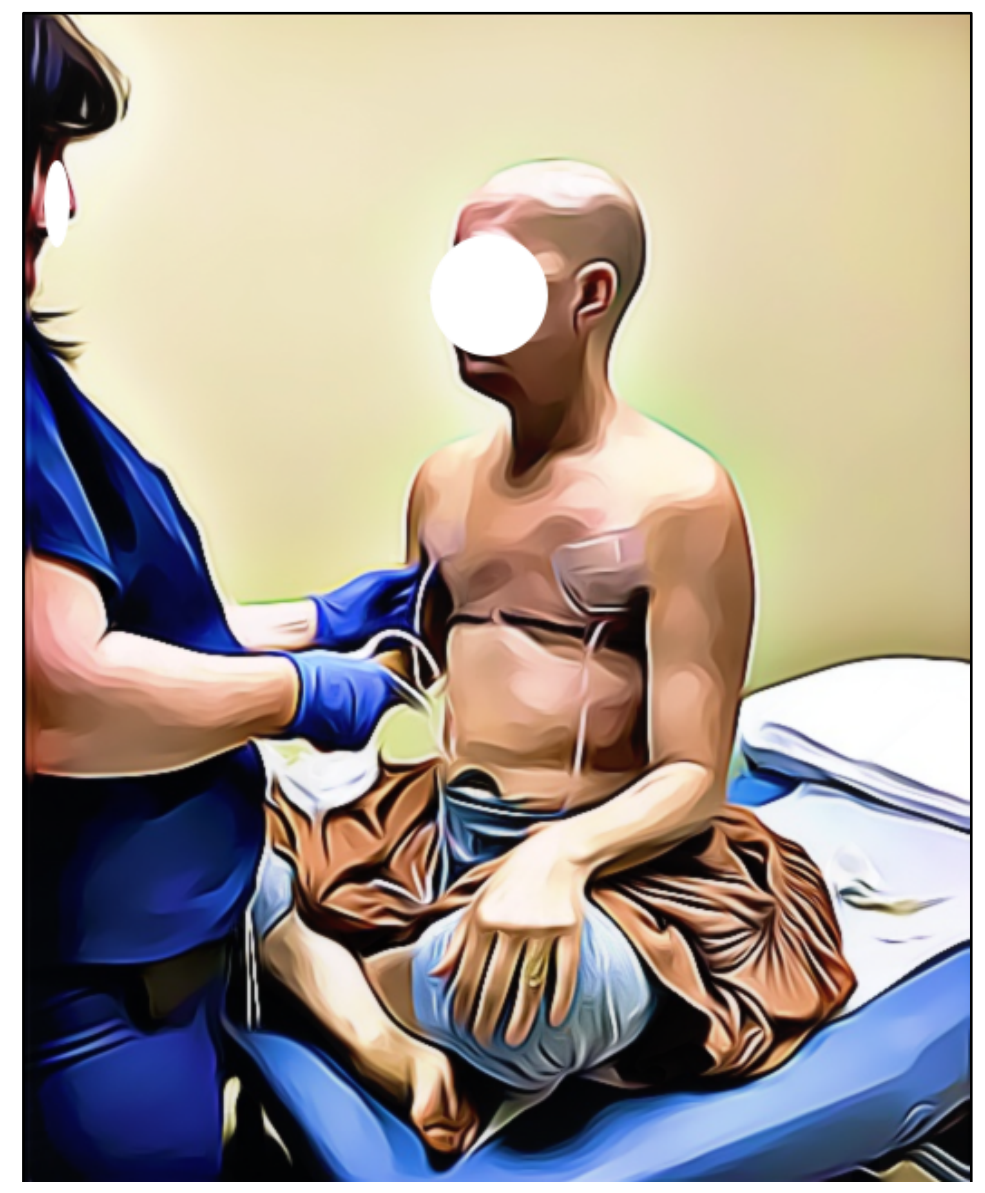

Gigi's caption with Figure 6 [1,196 Likes; 291 Comments]: my intention in sharing this photo is to shine light on the state of breast cancer treatment in 2017. it is not cute \& pink like \#Pinktober would have you believe.

$\infty$

$[\ldots]$

$i$ chose to remain flat \& not reconstruct. $i$ knew implants were not for me, it was an immediate intuitive response when my surgeon presented it as an option. part of posting this photo is to draw awareness to the fact that going flat is not the norm in BC treatment. most women get implants. $i$ have heard of women who had to undergo psychological evaluations before being cleared to go flat, luckily my surgeon was wiser than that. many other women aren't even told flat is an option. $i$ chose to go flat to simplify the treatment process (implants require many more procedures), avoid complications (many women's bodies reject the implants \& eventually remove them), \& i didn't want to put more hazardous \& potentially cancer causing materials in my body. $i$ don't judge women who choose implants, not at all. $i$ just know they are not for me.

$\infty$

it's wild to me that as a woman fights for her life, she also has to quickly decide about plastic surgery. this journey has taught me so much about how beauty is intrinsically woven into our identity \& value as women. being bald \& breastless is confronting on many levels. but i'm alive.

$\infty$

this post was so so hard to make. $i$ pray it raises awareness. 
Gigi's raw and unfiltered image is not the type shared in a mainstream context, particularly in the context of breast cancer. In line with recovery disclosures, her image challenges mainstream notions of recovery, thus normalising hidden aspects of the healthcare consumption experience. As Gigi alludes to in her caption, there is a mainstream cultural pinkwashing of breast cancer awareness (Sulik, 2010). Pink is considered representative of femininity and has become synonymous with breast cancer awareness (Lupton, 1994). However, the 'bubblegum' happiness associated with pink fails to captures the lived experience breast cancer patients must endure. The pinkwashing of breast cancer also suggests all breast cancer experiences are the same, which our data consistently disproves. Employing corporeal and recovery disclosures to engage in normalising practices, Gigi offers an incremental transformation of an underrepresented breast cancer experience - that of remaining flat after mastectomy. Following Gigi's post, she received over 1,000 likes and nearly 300 comments. Gigi responds thoughtfully to each comment, offering words of solidarity and sharing more detail about her experience. A particularly poignant exchange takes place over a series of comments between Gigi and a commenter, Marie.

Marie: Thank you so much for sharing this. As someone facing bilateral mastectomy in two weeks, I genuinely appreciate your honesty. And you're right I was not given the option of no reconstruction. So here I am, two weeks out, trying to decide what's best for me. Thanks again for your honesty.

Gigi: wow!! first of all... i'm loving you, you are not alone. it is such a surreal moment you are in. you will know exactly what is best for you, the answer will come may i ask, how was it framed to you? they didn't mention flat as an option? $\mathbb{G}$

Marie: At my big appointment with breast surgeon, oncologist and radiation oncologist... I was being examined by the breast surgeon and she was telling me the options of lumpectomy or bilateral mastectomy with reconstruction. I asked what about not doing the reconstruction? She said, no, you're too young and it would be too difficult emotionally for you. Of course, she didn't ask about me emotional state or anything like that.

\section{Gigi: OMG!!!!! what in the actual fuck!!!!!}

The conversation extends over the course of a few more comments, with Gigi finally asking Marie to keep her posted in the coming weeks. Gigi and Marie demonstrate how companionship unfolds, as facilitated by Instagram. Marie's gratitude points toward the transformative potential of social media to facilitate relationships and empathy, built upon shared experiences. While these two women may not know each other in real-life, they develop a bond quickly rooted in the shared interest of 'going flat' and more notably, the experiences of how this option is often hidden in the healthcare setting. Being flat is 
considered so culturally abnormal, doctors do not provide the option, shut down the option, or require additional psychological assessments. Gigi's effort to mainstream her decision, or at a minimum, share the reality of her situation, connects to Marie in real-time as she is in the midst of a similar decision. Gigi and Marie's discussion sheds light on the mainstream narratives of recovery and in contrast, by sharing their stories on Instagram, these women negotiate the abject body and challenge the mainstream medical conversation, in line with recovery disclosures. Most importantly, this is done in community - fostering companionship support through relying on one another as members of their extended support system.

\section{Discussion}

This research responds to calls to examine the changing role of the healthcare consumer, in particular the ways in which technology is harnessed by consumers to (co)create third places that offer social support for those experiencing vulnerability (McColl-Kennedy et al., 2017, Tang et al., 2015, Parkinson et al., 2017). Our research concludes that normalising hidden healthcare consumption experiences through visual storytelling on social media is an important means of fostering the social support needed to address the vulnerabilities of healthcare consumers and enhance their well-being. The digital affordances of image-based social media are fundamental in facilitating this process.

Our study demonstrates that vulnerable healthcare consumers engage in visual storytelling on Instagram through healthcare disclosures, namely procedural disclosures, corporeal disclosures and recovery disclosures. These disclosures work to normalise hidden healthcare consumption experiences through three normalising practices (providing learning resources, cohering the illness experience and problematising mainstream recovery narratives) and highlight implications for the healthcare service system. For a summary of these findings, see Table 2. In turn, this fosters social support between vulnerable healthcare consumers, specifically informational and companionship support - both of which inform one another. Informational support fostered through healthcare disclosures and normalising practices enable information to be exchanged in real-time to customised audiences, offering a level of support that other platforms or traditional support groups may not be able to readily provide. Moreover, this information is opened up to broader networks of relevance to vulnerable healthcare consumers, such as friends and family, in turn equipping them to better support their loved ones. Companionship support fostered through healthcare disclosures and 
normalising practices on Instagram is similarly unique for bringing together vulnerable healthcare consumers with niche yet similar experiences through real-time connections. Again, this enhances the nature of support offered. The ways in which healthcare disclosures, normalising practices, social support and digital affordances function collectively in the visual storytelling of vulnerable healthcare consumers on image-based social media is depicted in Figure 1.

Through exploring the lived experiences of vulnerable healthcare consumers and the unique perspectives they hold about their health and treatment (Tian et al., 2014), our study offers a 'view from within', which in turn provides healthcare service providers with insights into how healthcare consumers can be best supported for their well-being and where healthcare service gaps exist. Procedural disclosures highlight possibilities for information sharing in co-creating healthcare services. For example, healthcare consumers can collaborate with healthcare providers to develop informational content that can be shared to wider audiences, in turn facilitating understanding about certain procedures and working to allay concerns and fears that may arise as a result of this information remaining hidden. Corporeal disclosures open up myriad possibilities for healthcare providers to better understand the needs of and challenges faced by healthcare consumers as their bodies undergo incremental changes and transformations. Recovery disclosures may supplement traditional recovery intervention programs, which can be limited by geography, financial affordability and social stigma.

To enhance the support needed outside of the healthcare setting, healthcare services providers can point to the range of informational and companionship support that is facilitated through visual storytelling on image-based social media platforms. For example, healthcare consumers can be directed to the informational support offered through peer-to-peer recommendations about remedies and relief pertinent to the illness experience. Here, healthcare service providers can communicate how this information can be easily and readily accessed through niche hashtags or following digital health influencers - such as the women whose social media accounts were analysed for the purposes of this study. Whilst such information is now more widely available due to the nature of social media-based interactions, within the healthcare service setting such information gaps remain. Given the range of pressures placed upon healthcare service providers, this is moreover unlikely to change. Hence visual storytelling on social media provides a unique opportunity for healthcare service providers to point to available information critical to procedural, corporeal and recovery aspects of the healthcare consumption experience to improve the well-being of 
vulnerable healthcare consumers.

Similarly, in relation to companionship support, healthcare service providers can guide healthcare consumers to the extended support system available through image-based social media platforms. In our study, breast cancer patients and survivors formed deep connections and a shared sense of community with other 'breasties' as they bonded over shared and quite specific experiences. This companionship support was particularly heightened for those negotiating choices that challenged mainstream medical orthodoxy, such as the choice to remain 'flat' and not undertake reconstructive breast surgery. Hence, by having healthcare service providers direct healthcare consumers to such communities of support, companionship support can be heightened - particularly for moments of the care process that take place outside of the healthcare setting and in real-time as healthcare concerns unfold. Our study offers important pathways forward for healthcare service providers to supplement and offer informational and companionship support to vulnerable healthcare consumers, in turn creating transformative and supportive institutions that can offer enduring systems to improve societal well-being.

These findings both support and offer further insight to extant studies that highlight the power of social media to enable individuals to share their illness stories in direct and explicit ways to provide learning for others and a means of coping throughout the illness experience (Gonzalez-Dolginko, 2016, Chou et al., 2011, Keim-Malpass and Steeves, 2012, McCosker and Darcy, 2013, Yu et al., 2011). We call for further research to understand the potential of visual storytelling on social media to change how healthcare consumers perceive and manage their illness. For example, does this ability to relate to others with similar shared illness experiences normalise other aspects of the illness experience? What are the motives, aspirations and outcomes for consumers who use social media to narrate their healthcare experiences? Our research focused on the experiences of patients and survivors, but what about those who do not survive their illness? As Wong and King (2008) observe, breast cancer narratives are dominated by stories of restitution. So what are the implications of visual storytelling on social media that deviate from these more acceptable narratives? Whilst our study demonstrates how the breast cancer community on social media offers such challenges by disclosing the more abject, confronting and unspoken aspects of the illness, what does it mean when the story does not end in survival? Another avenue for research relates to the online safety of those that tell their stories, including concerns about personal information that is revealed being misused, online bullying and online harassment ( $\mathrm{Yu}$ et al., 2011). Finally, research should investigate whether normalising hidden consumption 
experiences through visual storytelling on social media can be witnessed in settings outside of healthcare and addresses consumer vulnerabilities in ways other than the facilitation of social support.

In conclusion, we contend that visual storytelling on image-based social media offers transformative possibilities for vulnerable healthcare consumers by normalising hidden healthcare consumption experiences, which in turn facilitates social support and enhances well-being. By engaging in visual storytelling on Instagram through healthcare disclosures, vulnerable healthcare consumers provide learning resources, cohere the illness experience and problematise mainstream recovery narratives, fostering both informational and companionship social support. These actions are facilitated and enabled by the digital affordances of the Instagram platform. Our research thus highlights the critical and interrelated role of both visual storytelling and social media in fostering social support and improving well-being for vulnerable consumers. Through a framework of visual storytelling for vulnerable healthcare consumers on image-based social media, our research offers three key contributions: (1) that visual storytelling fosters social support for vulnerable healthcare consumers; (2) recognising this occurs through normalising hidden healthcare consumption experiences; and (3) identifying healthcare disclosures, normalising practices and enabling digital affordances as fundamental to this process. In contributing to our understanding of healthcare services, our study highlights possible well-being shortcomings in the healthcare service system and the potential of visual storytelling through image-based social media in overcoming such deficiencies. Moreover, by resisting the cultural imperative of concealment for women with breast cancer (Wilkinson, 2001), the women in our study highlight the importance of both consumption and post-consumption experiences of healthcare services and the co-creative role of consumers in these. We call for greater consideration of the role of image-based social media in mediating healthcare consumption experiences, supporting wellbeing for vulnerable consumers and driving social change. 


\section{References}

Alfano, C. M. \& Rowland, J. H. 2006. Recovery Issues in Cancer Survivorship: A New Challenge for Supportive Care. The Cancer Journal, 12, 432-443.

Allen, J. D., Savadatti, S. \& Levy, A. G. 2009. The transition from breast cancer 'patient' to 'survivor'. Psychooncology, 18, 71-8.

Angell, C., Van Teijlingen, E., Hundley, V. \& Ryan, K. 2015. Users of the healthtalk.org breastfeeding webpages; their characteristics and views. Evidence Based Midwifery, 13, 54-58.

Armstrong, J. 2010. Naturalistic Inquiry. In: SALKIND, N. J. (ed.) Encyclopedia of Research Design. 1st Edition ed. London, UK: SAGE Publications.

Arora, N. K., Finney Rutten, L. J., Gustafson, D. H., Moser, R. \& Hawkins, R. P. 2007. Perceived helpfulness and impact of social support provided by family, friends, and health care providers to women newly diagnosed with breast cancer. Psychooncology, 16, 474-86.

Baker, S. M., Gentry, J. W. \& Rittenburg, T. L. 2005. Building Understanding of the Domain of Consumer Vulnerability. Journal of Macromarketing, 25, 128-139.

Baker, S. M., Hunt, D. M. \& Rittenburg, T. L. 2007. Consumer Vulnerability as a Shared Experience: Tornado Recovery Process in Wright, Wyoming. Journal of Public Policy \& Marketing, 26, 6-19.

Bateman, J. A. 2014. Text and Image: A Critical Introduction to the Visual/Verbal Divide, London, Routledge.

Belk, R. W. \& Tumbat, G. 2005. The Cult of Macintosh. Consumption Markets \& Culture, 8, 205-217.

Berkman, L. F., Glass, T., Brissette, I. \& Seeman, T. E. 2000. From social integration to health: Durkheim in the new millennium Social Science \& Medicine, 51, 843-857.

Berland, G. K., Elliott, M. N., Morales, L. S. \& Et Al. 2001. Health information on the internet: Accessibility, quality, and readability in english and spanish. JAMA, 285, 2612-2621.

Boyd, D. \& Crawford, K. 2012. Critical Questions for Big Data: Provocations for a cultural, technological, and scholarly phenomenon. Information, Communication \& Society, $15,662-679$.

Braun, V. \& Clarke, V. 2006. Using thematic analysis in psychology. Qualitative Research in Psychology, 3, 77-101.

Broderick, A. J., Demangeot, C., Adkins, N. R., Ferguson, N. S., Henderson, G. R., Johnson, G., Kipnis, E., Mandiberg, J. M., Mueller, R. D., Pullig, C., Roy, A. \& Zúñiga, M. A. 2011. Consumer Empowerment in Multicultural Marketplaces: Navigating Multicultural Identities to Reduce Consumer Vulnerability. Journal of Research for Consumers; Christchurch, 1-13.

Canhoto, A. I. \& Dibb, S. 2016. Unpacking the interplay between organisational factors and the economic environment in the creation of consumer vulnerability. Journal of Marketing Management, 32, 335-356.

Carlson, E. D., Engebretson, J. \& Chamberlain, R. M. 2006. Photovoice as a Social Process of Critical Consciousness. Qualitative Health Research, 16, 836-852.

Charmaz, K. 2002. Stories and Silences: Disclosures and Self in Chronic Illness. Qualitative Inquiry, 8, 302-328.

Chou, W.-Y. S., Hunt, Y., Folkers, A. \& Augustson, E. 2011. Cancer Survivorship in the Age of YouTube and Social Media: A Narrative Analysis. Journal of Medical Internet Research, 13. 
Chuang, K. Y. \& Yang, C. C. 2010. Helping you to help me: exploring supportive interaction in online health community. Proceedings of the 73rd ASIS\&T Annual Meeting on Navigating Streams in an Information Ecosystem - Volume 47. Pittsburgh, Pennsylvania: American Society for Information Science.

Cohen, S. E. \& Syme, S. 1985. Social support and health, Academic Press.

Cova, B. \& Pace, S. 2006. Brand community of convenience products: new forms of customer empowerment - the case "my Nutella The Community". European Journal of Marketing, 40, 1087-1105.

Datan, N. 1989. Illness and Imagery: Feminist Cognition, Socialization, and Gender Identity. In: CRAWFORD, M. \& GENTRY, M. (eds.) Gender and Thought: Psychological Perspectives. New York, NY: Springer New York.

Drew, S. E., Duncan, R. E. \& Sawyer, S. M. 2010. Visual Storytelling: A Beneficial But Challenging Method for Health Research With Young People. Qualitative Health Research, 20, 1677-1688.

Egan, R., Llewellyn, R., Wood, S., Doherty, J., Albert, T., Walsh, C., Atkinson, K. \& Kerslake, P. 2016. The Cancer Stories Project: narratives of encounters with cancer in Aotearoa, New Zealand. Psycho-Oncology, 25, 300-307.

Emilee, G., Ussher, J. M. \& Perz, J. 2010. Sexuality after breast cancer: A review. Maturitas, 66, 397-407.

Eysenbach, G., Nakata, Y., Rimer, B., Tsuya, A., Sugawara, Y., Tanaka, A. \& Narimatsu, H. 2014. Do Cancer Patients Tweet? Examining the Twitter Use of Cancer Patients in Japan. Journal of Medical Internet Research, 16.

Fobair, P., Stewart, S. L., Chang, S., D'onofrio, C., Banks, P. J. \& Bloom, J. R. 2006. Body image and sexual problems in young women with breast cancer. Psychooncology, $15,579-94$.

Frank, A. 1997. Illness as moral occasion: restoring agency to ill people. Health:, 1, 131148.

Frank, A. 2000. The Standpoint of Storyteller. Qualitative Health Research, 10, 354-365.

Frank, A. 2013. The wounded storyteller : body, illness, and ethics, Chicago, The University of Chicago Press.

Frith, H., Harcourt, D. \& Fussell, A. 2007. Anticipating an altered appearance: Women undergoing chemotherapy treatment for breast cancer. European Journal of Oncology Nursing, 11, 385-391.

Gentry, J. W. \& Goodwin, C. 1995. Social Support for Decision Making During Grief Due to Death. American Behavioral Scientist, 38, 553-563.

Gonzalez-Dolginko, B. 2016. Picture of health: An artist's journey through disease as told in his photographs. Journal of Applied Arts \& Health, 7, 369-389.

Gucciardi, E., Jean-Pierre, N., Karam, G. \& Sidani, S. 2016. Designing and delivering facilitated storytelling interventions for chronic disease self-management: a scoping review. BMC Health Services Research; London, 16.

Hamilton, K. 2009. Those Left Behind: Inequality in Consumer Culture. Irish Marketing Review; Dublin, 20, 40-54.

Helms, R. L., O'hea, E. L. \& Corso, M. 2008. Body image issues in women with breast cancer. Psychol Health Med, 13, 313-25.

Høybye, M. T., Johansen, C. \& Tjørnhøj-Thomsen, T. 2005. Online interaction. Effects of storytelling in an internet breast cancer support group. Psycho-Oncology, 14, 211220. 
Jiang, L. C., Bazarova, N. N. \& Hancock, J. T. 2011. The Disclosure-Intimacy Link in Computer-Mediated Communication: An Attributional Extension of the Hyperpersonal Model. Human Communication Research, 37, 58-77.

Kaiser, K. 2008. The meaning of the survivor identity for women with breast cancer. Social Science \& Medicine, 67, 79-87.

Keim-Malpass , J. \& Steeves, R. H. 2012. Talking With Death at a Diner: Young Women's Online Narratives of Cancer. Oncology Nursing Forum, 39, 373-378.

Keim-Malpass, J., Steeves, R. H. \& Kennedy, C. 2014. Internet ethnography: a review of methodological considerations for studying online illness blogs. Int J Nurs Stud, 51, 1686-92.

Kim, S. 2009. Content analysis of cancer blog posts. Journal of the Medical Library Association : JMLA, 97, 260-266.

Kitchin, R. \& Lauriault, T. P. 2015. Small data in the era of big data. GeoJournal, 80, 463475.

Kozinets, R., Hemetsberger, A. \& Schau, H. 2008. The Wisdom of Consumer Crowds: Collective Innovation in the Age of Networked Marketing. Journal of Macromarketing, 28, 339.

Laestadius, L. 2017. Instagram. In: SLOAN, L. \& QUAN-HAASE, A. (eds.) The SAGE Handbook of Social Media Research Methods. London, UK: SAGE Publications.

Laestadius, L. \& Wahl, M. M. 2017. Mobilizing social media users to become advertisers: Corporate hashtag campaigns as a public health concern. Digital Health, 3, 1-12.

Langellier, K. M. \& Sullivan, C. F. 1998. Breast Talk in Breast Cancer Narratives. Qualitative Health Research.

Lau, V. 2017. Visual Aid. Medical Marketing \& Media, 52, 42-43.

Ledbetter, A. M., Mazer, J. P., Degroot, J. M., Meyer, K. R., Yuping, M. \& Swafford, B. 2011. Attitudes Toward Online Social Connection and Self-Disclosure as Predictors of Facebook Communication and Relational Closeness. Communication Research, 38, 27-53.

Lee, E., Lee, J.-A., Moon, J. H. \& Sung, Y. 2015. Pictures Speak Louder than Words: Motivations for Using Instagram. Cyberpsychology, Behavior, and Social Networking, 18, 552-556.

Lee, R., Ozanne, J. L. \& Hill, R. P. 1999. Improving Service Encounters Through Resource Sensitivity: The Case of Health Care Delivery in an Appalachian Community. Journal of Public Policy \& Marketing, 18, 230-248.

Lemke, J. 1998. Multiplying Meaning: Visual and Verbal Semiotics in Scientific Text. In: MARTIN, M. A. \& VEEL, R. (eds.) Reading Science. London: Routledge.

Lomanowska, A. M. \& Guitton, M. J. 2016. Online intimacy and well-being in the digital age. Internet Interventions, 4, 138-144.

Lupton, D. 1994. Femininity, Responsibility, and the Technological Imperative: Discourses on Breast Cancer in the Australian Press , Femininity, Responsibility, and the Technological Imperative: Discourses on Breast Cancer in the Australian Press. International Journal of Health Services, 24, 73-89.

Mathwick, C., Wiertz, C. \& De ruyter, K. 2008. Social Capital Production in a Virtual P3 Community. Journal of Consumer Research, 34, 832-849.

Mccoll-Kennedy, J., R. , Snyder, H., Elg, M., Witell, L., Helkkula, A., Hogan, S. \& Anderson, L. 2017. The changing role of the health care customer: review, synthesis and research agenda. Journal of Service Management, 28, 2-33. 
Mccoll-Kennedy , J., Vargo, S. L., Dagger, T. S., Sweeney, J. C. \& Kasteren, Y. V. 2012. Health Care Customer Value Cocreation Practice Styles. Journal of Service Research, 15, 370-389.

Mccormack, A. 2010. Individuals With Eating Disorders and the Use of Online Support Groups as a Form of Social Support. CIN: Computers, Informatics, Nursing, 28, $12-$ 19.

Mccosker, A. \& Darcy, R. 2013. Living with Cancer. Information, Communication \& Society, 16, 1266-1285.

Mccurdy, K. 2016. Visual storytelling in healthcare: Why we should help patients visualize their health. Information Visualization; Thousand Oaks, 15, 173-178.

Mckeage, K., Crosby, E. \& Rittenburg, T. 2018. Living in a Gender-Binary World.Journal of Macromarketing, 38, 73-90.

Meric, F., Bernstam, E. V., Mirza, N. Q., Hunt, K. K., Ames, F. C., Ross, M. I., Kuerer, H. M., Pollock, R. E., Musen, M. A. \& Singletary, S. E. 2002. Breast cancer on the world wide web: cross sectional survey of quality of information and popularity of websites. BMJ, 324, 577-581.

Mishler, E. G. 1984. The discourse of medicine: The dialectics of medical interviews, Norwood, NJ, Ablex.

Northouse, L. L., Mood, D., Kershaw, T., Schafenacker, A., Mellon, S., Walker, J., Galvin, E. \& Decker, V. 2002. Quality of Life of Women With Recurrent Breast Cancer and Their Family Members. Journal of Clinical Oncology, 20, 4050-4064.

O'sullivan, S. R. 2015. The Market Maven Crowd: Collaborative Risk-Aversion and Enhanced Consumption Context Control in an Illicit Market. Psychology \& Marketing, 32, 285-302.

Olsson, E. \& Lau, M. 2015. When one size does not fit all: Using participatory action research to co-create preventive healthcare services. Action Research, 13, 9-29.

Orgad, S. 2005. The Transformative Potential of Online Communication. Feminist Media Studies, 5, 141-161.

Page, R. E. 2012. Stories and social media identities and interaction, New York, Routledge.

Parkinson, J., Schuster, L., Mulcahy, R. \& Taiminen, H. M. 2017. Online support for vulnerable consumers: a safe place? Journal of Services Marketing, 31, 412-422.

Pelusi, J. 2006. Sexuality and Body Image: Research on breast cancer survivors documents altered body image and sexuality. Cancer Nursing, 29, 32-38.

Pittman, M. \& Reich, B. 2016. Social media and loneliness: Why an Instagram picture may be worth more than a thousand Twitter words. Computers in Human Behavior, 62, 155-167.

Price, L. \& Arnould, E. 1999. Commerical friendships: Service provider--client relationships in context. Journal of Marketing, 63, 38-56.

Price, L., Feick, L. \& Guskey, A. 1995. Everyday Market Helping Behavior. Journal of Public Policy \& Marketing, 14, 255-266.

Rosenbaum, M. S. 2009. Exploring commercial friendships from employees' perspectives. Journal of Services Marketing, 23, 57-66.

Rosman, S. 2004. Cancer and stigma: experience of patients with chemotherapy-induced alopecia. Patient Education and Counseling, 52, 333-339.

Russell-Bennett, R., Wood, M. \& Previte, J. 2013. Fresh ideas: services thinking for social marketing. Journal of Social Marketing, 3, 223-238.

Sawka, C. A., Goel, V., Mahut, C. A., Taylor, G. A., Thiel, E. C., O'connor, A. M., Ackerman, I., Burt, J. H. \& Gort, E. H. 1998. Development of a patient decision aid for choice of surgical treatment for breast cancer. Health Expectations, 1, 23-36. 
Schuster, L., Drennan, J. \& Lings, I. 2013. Consumer acceptance of m-well-being services: a social marketing perspective. European Journal of Marketing, 47, 1439-1457.

Shultz, C. J. \& Holbrook, M. B. 2009. The Paradoxical Relationships Between Marketing and Vulnerability. Journal of Public Policy \& Marketing, 28, 124-127.

Singh, S. K. 2018. Destigmatization of the fat female body in Size Zero and Dum Laga ke Haisha. Fat Studies, 1-17.

Sulik, G. A. 2010. Pink Ribbon Blues: How Breast Cancer Culture Undermines Women's Health, Oxford, New York, Oxford University Press.

Taggart, L. R., Ozolins, L., Hardie, H. \& Nyhof-Young, J. 2009. Look good feel better workshops: a "big lift" for women with cancer. J Cancer Educ, 24, 94-9.

Tang, Y., Qiuying, Z. \& Xiucheng, F. 2015. The Impact of Online Social Support on Patients' Quality of Life and the Moderating Role of Social Exclusion. Journal of Service Research, 18, 369-383.

Thompson, C. J. 1997. Interpreting Consumers: A Hermeneutical Framework for Deriving Marketing Insights from the Texts of Consumers' Consumption Stories. Journal of Marketing Research, 34, 438-455.

Tian, K., Sautter, P., Fisher, D., Fischbach, S., Luna-Nevarez, C., Boberg, K., Kroger, J. \& Vann, R. 2014. Transforming Health Care: Empowering Therapeutic Communities through Technology-Enhanced Narratives. Journal of Consumer Research, 41, 237-260.

Varre, P. \& Slettebø, Å. 2011. 'It's about my life'. Cancer patients'coping potential, as expressed through their messages in an online discussion forum. Nordic Journal of Nursing Research \& Clinical Studies / Vård i Norden, 31, 4-8.

Visconti, L. M. 2016. A conversational approach to consumer vulnerability: performativity, representations, and storytelling. Journal of Marketing Management, 32, 371-385.

Wang, C., Yi, W. K., Tao, Z. W. \& Carovano, K. 1998. Photovoice as a participatory health promotion strategy. Health Promotion International, 13, 75-86.

Wang, J. J. \& Tian, Q. 2014. Consumer Vulnerability and Marketplace Exclusion: A Case of Rural Migrants and Financial Services in China. Journal of Macromarketing, 34, 45-56.

Wilkinson, S. 2001. Breast Cancer: Feminism, Representations and Resistance - a Commentary on Dorothy Broom's 'Reading Breast Cancer' , Breast Cancer: Feminism, Representations and Resistance - a Commentary on Dorothy Broom's 'Reading Breast Cancer'. Health, 5, 269-277.

Wong, N. \& King, T. 2008. The Cultural Construction of Risk Understandings through Illness Narratives. Journal of Consumer Research, 34, 579-594.

Yaphe, J., Rigge, M., Herxheimer, A., Mcpherson, A., Miller, R., Shepperd, S. \& Ziebland, S. 2000. The use of patients' stories by self-help groups: a survey of voluntary organizations in the UK on the register of the College of Health. Health Expectations, 3, 176-181.

Yu, J., Taverner, N. \& Madden, K. 2011. Young people's views on sharing health-related stories on the Internet. Health \& Social Care in the Community, 19, 326-334.

Zhu, R., Dholakia, U. M., Chen, X. \& Algesheimer, R. 2012. Does online community participation foster risky financial behavior?(Report). Journal of Marketing Research, 49, 394.

Ziebland, S., Chapple, A., Dumelow, C., Evans, J., Prinjha, S. \& Rozmovits, L. 2004. How the internet affects patients' experience of cancer: a qualitative study. BMJ, 328, 564. 